\title{
Fractalkine Signaling in Microglia Contributes to Ectopic Orofacial Pain following Trapezius Muscle Inflammation
}

\author{
Masaaki Kiyomoto, ${ }^{1,2}$ Masamichi Shinoda, ${ }^{2,3}$ Akiko Okada-Ogawa, ${ }^{1}$ Noboru Noma, ${ }^{1}$ Kazuo Shibuta, ${ }^{2}$ Yoshiyuki Tsuboi, ${ }^{2}$ \\ Barry J. Sessle, ${ }^{4}$ Yoshiki Imamura, ${ }^{1}$ and Koichi Iwata ${ }^{2,3,5}$ \\ Departments of ${ }^{1}$ Oral Diagnosis and ${ }^{2}$ Physiology and ${ }^{3}$ Division of Functional Morphology, Dental Research Center, Nihon University School of Dentistry, \\ Tokyo 101-8310, Japan, ${ }^{4}$ Department of Oral Physiology, Faculty of Dentistry, University of Toronto, Toronto, Ontario M5S 1A8, Canada, and ${ }^{5}$ Division of \\ Applied System Neuroscience, Advanced Medical Research Center, Nihon University Graduate School of Medical Science, Tokyo 173-8610, Japan
}

Fractalkine (FKN) signaling is involved in mechanical allodynia in the facial skin following trapezius muscle inflammation. Complete Freund's adjuvant (CFA) injection into the trapezius muscle produced mechanical allodynia in the ipsilateral facial skin that was not associated with facial skin inflammation and resulted in FKN but not FKN receptor (CX3CR1) expression, and microglial activation was enhanced in trigeminal spinal subnucleus caudalis $(\mathrm{Vc})$ and upper cervical spinal cord (C1-C2). Intracisterna magna anti-CX3CR1 or anti-interleukin (IL)- $1 \beta$ neutralizing antibody administration decreased the enhanced excitability of $\mathrm{Vc}$ and $\mathrm{C} 1-\mathrm{C} 2$ neurons in CFA-injected rats, whereas intra-cisterna magna FKN administration induced microglial activation and mechanical allodynia in the facial skin. IL- $1 \beta$ expression and p38 mitogen-activated protein kinase phosphorylation were enhanced in activated microglia after CFA injection. The excitability of neurons whose receptive fields was located in the facial skin was significantly enhanced in CFA-injected rats, and the number of cells expressing phosphorylated extracellular signal-regulated kinase (pERK) following noxious mechanical stimulation of the facial skin was significantly increased in Vc and C1-C2. We also observed mechanical allodynia of the trapezius muscle as well as microglial activation and increased pERK expression in C2-C6 after noxious stimulation of the trapezius muscle in facial skin-inflamed rats. These findings suggest that FKN expression was enhanced in $\mathrm{Vc}$ and $\mathrm{C} 1-\mathrm{C} 2$ or $\mathrm{C} 2-\mathrm{C} 6$ following trapezius muscle or facial skin inflammation, microglia are activated via FKN signaling, IL-1 $\beta$ is released from the activated microglia, and the excitability of neurons in Vc and C1-C2 or C2-C6 is enhanced, resulting in the ectopic mechanical allodynia.

\section{Introduction}

It is well known that patients suffering from neck muscle pain sometimes complain of headache or tenderness in the orofacial musculatures (Zhang and Dellon, 2008; Fernández-de-Las-Peñas et al., 2010). Since pain may occur in areas far away from the inflammation or nerve injury, this complicates diagnosis and treatment (Marini et al., 2012). The underlying pathophysiology associated with such pain is still poorly understood.

Received Oct. 24, 2012; revised March 15, 2013; accepted March 20, 2013.

Author contributions: M.K., M.S., Y.I., and K.I. designed research; M.K., A.O.-0., K.S., and Y.T. performed research; Y.T. contributed unpublished reagents/analytic tools; M.K., M.S., and N.N. analyzed data; M.S., B.J.S., and K.I. wrote the paper.

This work was supported by research grants from the Sato and Uemura Funds (M.S.) and the Dental Research Center, Nihon University School of Dentistry; a Nihon University multidisciplinary research grant and individual research grant; grants from the Ministry of Education, Culture, Sports, Science and Technology to promote multidisciplinary research projects [KAKENHI, Grant-in-Aid for Young Scientists (B), Grants 22792021 (M.S.) and 24659832 (K.I.)] and projects "Brain Mechanisms for Cognition, Memory and Behavior" and "Translational Research Network on Orofacial Neurological Disorders" at Nihon University; a grant from the Japan-Canada (Canadian Institutes of Health Research) Joint Health Research Program; and NIH Grant DE4786 to B.J.S., who is the holder of a Canadian Research Chair.

The authors declare no competing financial interests.

Correspondence should be addressed to Dr. Masamichi Shinoda, Department of Physiology, Nihon University School of Dentistry, 1-8-13 Kandasurugadai, Chiyoda-ku, Tokyo 101-8310, Japan. E-mail: shinoda.masamichi@nihon-u.ac.jp.

DOI:10.1523/JNEUROSCI.4968-12.2013

Copyright $\odot 2013$ the authors $\quad 0270-6474 / 13 / 337667-14 \$ 15.00 / 0$
It is unlikely that primary afferent fibers from the trapezius muscle and facial skin project the same neurons in the medullae, because primary afferent fibers from the trapezius muscle terminate in the $\mathrm{C} 2$ to $\mathrm{C} 6$ spinal segments, and those from the facial skin terminate in trigeminal spinal subnucleus caudalis $(\mathrm{Vc})$ and upper cervical spinal cord (C1-C2) spinal segments (Ishii, 1989; Takemura et al., 1991). These findings indicate that the Vc and $\mathrm{C} 1-\mathrm{C} 2$ neurons do not receive direct inputs from the trapezius muscle and C2-C6 neurons do not receive direct inputs from the facial skin.

Among the glial cells in the CNS, microglia are the resident macrophages, and their activation, analyzed by immunoreactivity of ionized calcium-binding adaptor molecule-1 (Iba1), can be induced by peripheral inflammation (Zhang et al., 2005; Haraguchi et al., 2012). Activated microglia exhibit a morphological change from a ramified shape to an amoeboid shape, an increase in proliferation, and an upregulation of Iba1 (Imai et al., 1996; Imai and Kohsaka, 2002). Furthermore, emerging data suggest that the microglial hyperactivation is involved in the generation of central sensitization via the production of pronociceptive inflammatory mediators, thus contributing to inflammatory pain (Ren and Torres, 2009; Gao and Ji, 2010).

Fractalkine (FKN) is a member of the chemokine family and is constitutively produced by neurons in the brain, spinal cord, and dorsal root ganglia (DRG) (Nishiyori et al., 1998). The cleaved 
FKN from the neuronal cell membrane enzymatically binds directly to FKN receptor (CX3CR1) localizing in the spinal microglia (Bazan et al., 1997; Gao and Ji, 2010; Staniland et al., 2010). Moreover, intra-cisterna magna (i.c.m.) administration of cathepsin S (CatS) induces mechanical allodynia in wild-type but not CX3CR1-null mice (Clark et al., 2007). CatS inhibitor prevents the increase of FKN release and partially reduces established mechanical hyperalgesia induced by peripheral nerve injury (Barclay et al., 2007; Clark et al., 2009). These findings suggest that FKN cleaved from the neuronal membrane plays a role in the establishment and maintenance of persistent pain behaviors (Staniland et al., 2010; Clark and Malcangio, 2012).

In the present study, we developed an animal model of ectopic orofacial pain established by trapezius muscle inflammation induced by complete Freund's adjuvant (CFA) injection. To clarify the possible role of FKN and its receptor in the ectopic orofacial pain associated with trapezius muscle inflammation, we examined the expression of CX3CR1 in $\mathrm{Vc}$ and $\mathrm{C} 1-\mathrm{C} 2$. We also investigated whether the trapezius muscle became hypersensitive to mechanical stimulation following facial skin inflammation. Moreover, we investigated the functional significance of FKN and the morphological changes in microglia in relation to the ectopic pain.

\section{Materials and Methods}

\section{Animals}

Male Sprague Dawley rats (Japan SLC) weighing 210-260 g were used in all experiments $(n=474)$. Rats were maintained in a climate-controlled room on a $12 \mathrm{~h}$ light/dark cycle (lights on at 7:00 A.M.) with food and water available ad libitum. Efforts were made to minimize the number of animals used and their suffering. This study was conducted in accordance with the ethical guidelines of the International Association for the Study of Pain (Zimmermann, 1983) and was approved by the local animal ethics committee in accordance with the Guidelines for Animal Experimentation of Nihon University.

\section{Trapezius muscle and facial skin inflammation}

The rats were initially anesthetized with sodium pentobarbital $(50 \mathrm{mg} /$ $\mathrm{kg}$, i.p.) and placed on a warm mat $\left(37^{\circ} \mathrm{C}\right)$. To produce trapezius muscleinflamed rats, an incision was made on the neck skin to expose the trapezius muscle, $30 \mu \mathrm{l}$ of CFA ( $15 \mu \mathrm{l}$ of CFA mixed with $15 \mu \mathrm{l}$ of saline; Sigma-Aldrich) or saline (as vehicle control) was injected into the trapezius muscle, and then the neck skin was sutured with 5-0 silk. To produce facial skin-inflamed rats, $30 \mu \mathrm{l}$ of CFA ( $15 \mu \mathrm{l}$ of CFA mixed with $15 \mu \mathrm{l}$ of saline) or saline (as vehicle control) was injected into the facial skin. After surgery, benzyl penicillin potassium $(20,000 \mathrm{U}$, penicillin $\mathrm{G}$ potassium; Meiji Seika) was administered intramuscularly to prevent infection. To visualize the pathological changes in the facial skin and trapezius muscle before and after CFA injection, sections of these tissues were analyzed by hematoxylin and eosin staining.

\section{Assessment of mechanical sensitivity}

Rats were maintained in a climate-controlled room with water unavailable for $1 \mathrm{~d}$ before the daily training session, and could receive water intermittently during mechanical stimulation to the whisker pad skin or trapezius muscle in the session. For the $5 \mathrm{~d}$ session, the rats were trained to voluntarily protrude their snouts for $20 \mathrm{~min}$ from a cage through a small opening in its front wall (Kitagawa et al., 2006). The rats were not restricted and could escape freely from the mechanical stimulation under this condition. To assess changes in nociceptive threshold to mechanical stimulation of the lateral facial skin in the side ipsilateral to CFA or saline injection before and for $15 \mathrm{~d}$ after CFA injection into trapezius muscle, the von Frey filaments (Touch Test Sensory Evaluator; North Coast Medical) were applied to the lateral facial skin (Fig. $1 A$, inset). The headwithdrawal threshold (HWT) was measured from five trials. For each trial, the filament was applied at $1 \mathrm{~s}$ intervals. To assess changes in nociceptive threshold to mechanical stimulation of the trapezius muscle on the side ipsilateral to CFA or saline injection into facial skin on Day 4, the von Frey filaments and an electronic von Frey anesthesiometer (diameter, $5 \mathrm{~mm}$; Bioseb) were applied to the skin overlying the trapezius muscle. The body-withdrawal threshold (BWT) was measured for five trials. For each trial, the filament was applied at $1 \mathrm{~s}$ intervals. The HWT and BWT in each trial were determined as the minimum pressure intensity evoking the withdrawal in response to more than three of five stimuli. The interval between each mechanical stimulus was set at $>3$ min to avoid sensitization of the receptive field by frequent stimulus, and the rats kept their heads protruding through the opening of the wall during the behavioral testing under this condition. All behavioral tests were conducted during the light part of the light/dark cycle under blind conditions.

\section{Intra-cisterna magna administration of anti-CX3CR1 neutralizing antibody}

CFA or saline was injected into the trapezius muscle under deep anesthesia and the rat was simultaneously placed in a stereotaxic frame. Briefly, after a midline skin incision, a midline opening was made in the caudal part of the skull with a dental drill to insert a polyethylene tube (SP45; size, $0.5 \times 0.8 \mathrm{~mm}$; Natsume) into the cisterna magna (Terayama et al., 2008). To assess the involvement of CX3CR1 in the mechanical allodynia in the facial skin induced by CFA injection into the trapezius muscle, anti-CX3CR1 neutralizing antibody ( $3 \mu \mathrm{g} / \mathrm{d}$; purified rabbit anti-rat CX3CR1; Torrey Pines Biolabs) dissolved in physiological saline was administered intra-cisterna magnally for 4 successive days (Day 0 through Day 4) using a microosmotic infusion pump (Model 2001; Alzet Durect) connected to the polyethylene tube. The micro-osmotic infusion pump and the polyethylene tube were implanted subcutaneously in the contralateral trapezius muscle so as not to interfere with testing the ipsilateral trapezius muscle. On Day 4 after CFA injection, the HWT to mechanical stimulation was measured, and anti-CX3CR1 neutralizing antibody was continually administered during the behavioral measurement.

\section{Intra-cisterna magna administration of FKN}

To assess the involvement of FKN in the mechanical allodynia of facial skin induced by CFA injection into the trapezius muscle, FKN (R \& D Systems) dissolved in physiological saline $(72 \mu \mathrm{g} / \mathrm{d})$ or vehicle was administered into the cisterna magna by using an implanted microosmotic infusion pump for 4 successive days (Day 0 through Day 4 ) in naive rats. On Day 4, the HWT to mechanical stimulation of the facial skin was assessed.

\section{Intra-cisterna magna administration of $I L-1 \beta$}

To assess the involvement of IL- $1 \beta$ in the mechanical allodynia of the facial skin induced by CFA injection into the trapezius muscle, rabbit anti-rat IL- $1 \beta$ neutralizing antibody (Abcam) dissolved in 10\% PBS (1: $100,0.24 \mu \mathrm{l} / \mathrm{d}$ ) or vehicle was administered into the cisterna magna by using an implanted micro-osmotic infusion pump for 4 successive days (Day 0 through Day 4) in CFA- or saline-injected rats. On Day 4, the HWT to mechanical stimulation was also assessed.

\section{Motor performance}

Rota-Rod performance assessment. To rule out the possibility that motor impairment caused by intra-cisterna magna administration might have affected the behavioral data, each rat's coordination/motor performance was measured using a Rota-Rod apparatus (Type 477700; Ugo Basile) before and on Day 4 after CFA or saline injection, and anti-CX3CR1 neutralizing antibody was continually administered during behavioral measurement. Briefly, in a training session that was performed for $3 \mathrm{~d}$ before the test session, the rat was placed on the rod that was set to $4 \mathrm{rpm}$ over a $180 \mathrm{~s}$ period, and the performance time that each rat was able to remain on the Rota-Rod was recorded. The rat was subjected to three training trials at $2 \mathrm{~h}$ intervals for acclimation purposes. In the test session, the rat was placed on the Rota-Rod and their performance time was recorded up to a cutoff time of $180 \mathrm{~s}$. Each rat was tested three times at intervals of $2 \mathrm{~h}$ before and on Day 4 after CFA or saline injection, and the 

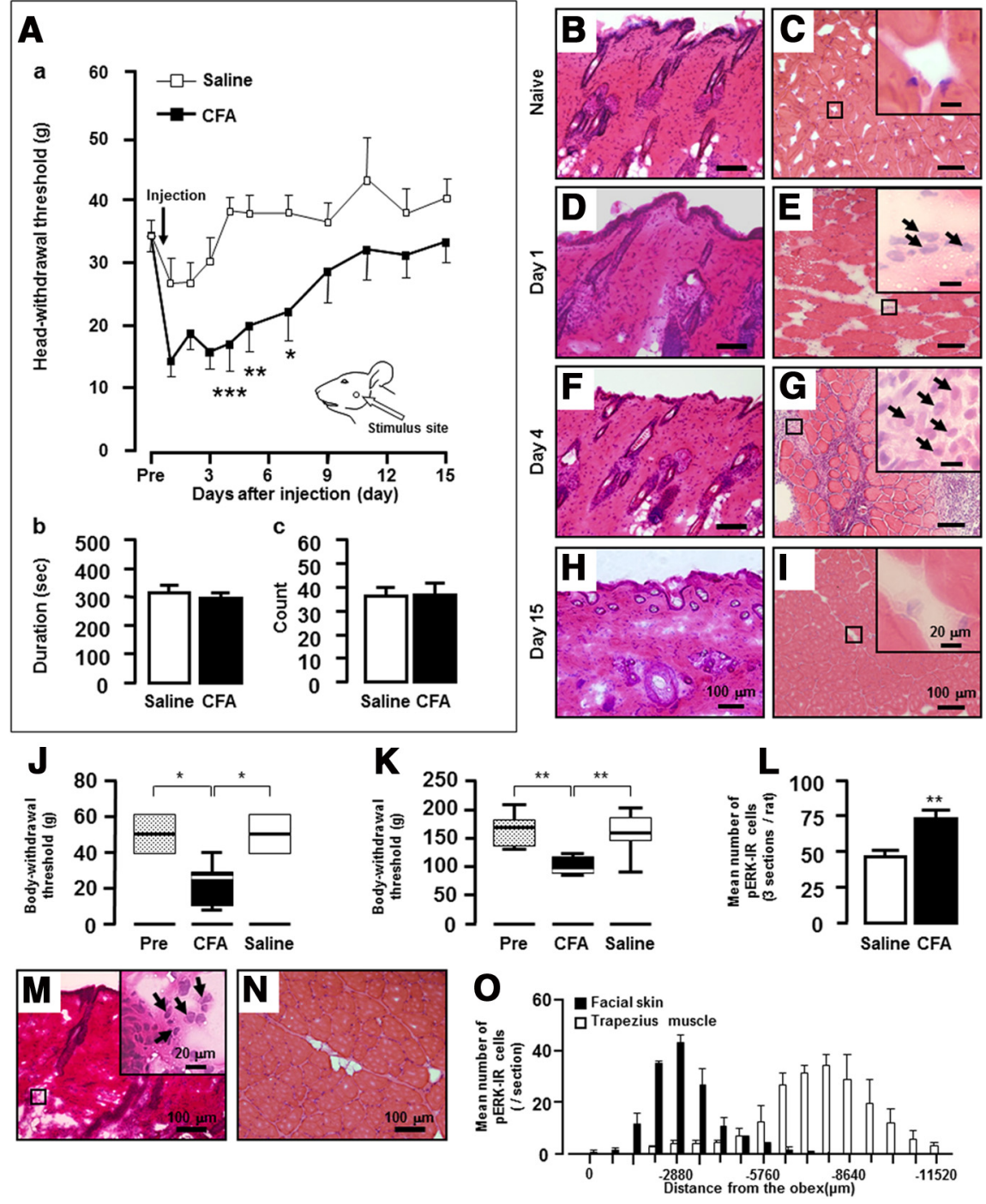

Figure 1. $\boldsymbol{A a}$, Changes in mechanical sensitivity measured in facial skin for $15 \mathrm{~d}$ after CFA or saline injection into the ipsilateral trapezius muscle. ${ }^{*} p<0.05 ;{ }^{* *} p<0.01 ;{ }^{* * *} p<0.001$ (compared with saline-injected rats; $n=10$ in each group; two-way ANOVA with repeated measures, followed by Bonferroni's multiple-comparison tests). The inset indicates the stimulus site. $\boldsymbol{A} \boldsymbol{b}, \boldsymbol{A} \boldsymbol{c}$, The duration $(\boldsymbol{A} \boldsymbol{b})$ and the number $(\boldsymbol{A c})$ of approaches to the water tap on Day 4 after CFA injection into the trapezius muscle ( $n=5$ in each). $\boldsymbol{B}-\boldsymbol{I}$, Representative histology of facial skin $(\boldsymbol{B}, \boldsymbol{D}, \boldsymbol{F}, \boldsymbol{H})$ and trapezius muscle $(\boldsymbol{C}$, $\boldsymbol{E}, \boldsymbol{G}, \boldsymbol{I})$ before $(\boldsymbol{B}, \boldsymbol{C})$ and on Day $1(\boldsymbol{D}, \boldsymbol{E})$, Day $4(\boldsymbol{F}, \boldsymbol{G})$, and Day $15(\boldsymbol{H}, \boldsymbol{I})$ following $(F A$ injection into the trapezius muscle. $\boldsymbol{C}, \boldsymbol{E}, \boldsymbol{G}, \boldsymbol{I}$, Insets show high-magnification photomicrographs. Arrows indicate lymphocytes. $\boldsymbol{B}-\boldsymbol{I}$, Scale bars in panels indicate $100 \mu \mathrm{m}$, and scale bars in inset indicate $20 \mu \mathrm{m}$. J, Changes in the mechanical sensitivity of trapezius muscle measured by the von Frey filaments before and on Day 4 after (FA or saline injection into the facial skin. ${ }^{*} p<0.05$ (one-way ANOVA with repeated measures, followed by Bonferroni's multiple-comparison tests; $n=6$ or 7 in each group). $\boldsymbol{K}$, Changes in mechanical sensitivity of trapezius muscle measured by the electronic von Frey anesthesiometer before and on Day 4 after CFA or saline injection into the facial skin. ${ }^{* *} p<0.01$ (one-way ANOVA with repeated measures, followed by Bonferroni's multiple-comparison tests; $n=6$ or 7 in each group). $L$, Changes in the number of pERK-IR cells in C2-C6 following noxious mechanical stimulation of trapezius muscle on Day 4 after saline or CFA injection into the facial skin. ${ }^{* *} p<0.01$ (Student's $t$ tests; $n=6$ or 7 in each group). $\boldsymbol{M}, \boldsymbol{N}$, Representative histology of facial skin $(\boldsymbol{M})$ and trapezius muscle $(\boldsymbol{N})$ on Day 4 following CFA injection into the facial skin. $\boldsymbol{M}$, Insets show high-magnification photomicrographs indicated by boxes. Arrows indicate lymphocytes. $\mathbf{0}$, The number of pERK-IR cells in Vc and C1-C6 following capsaicin injection into the facial skin or trapezius muscle ( $n=3$ in each).

three measurements were averaged. During behavioral measurement, anti-CX3CR1 neutralizing antibody was administered continually.

Water tap reaching performance assessment. To rule out the possibility that motor impairment of the trapezius muscle caused by CFA injection might have affected the behavioral data, each rat's coordination/motor performance was measured on Day 4 after CFA or saline injection. Briefly, rats were maintained in a climate-controlled room with food and water unavailable for $1 \mathrm{~d}$. Then the duration and the number of attempts to reach a water tap set $5 \mathrm{~cm}$ above the head were measured during 30 min. The measurements were performed on Day 4 after CFA or saline injection.

\section{Immunohistochemistry for Ibal or extracellular signal-regulated} kinase phosphorylation

On Days 4 and 15 after CFA or saline injection into the trapezius muscle, separate groups of rats were anesthetized with sodium pentobarbital $(50 \mathrm{mg} / \mathrm{kg}$, i.p.) and transcardially perfused with saline followed by a fixative containing $4 \%$ paraformaldehyde in $0.1 \mathrm{~m}$ phosphate buffer, $\mathrm{pH} 7.4$.

To assess the involvement of CX3CR 1 in microglial activation in Vc and C1-C2 induced by CFA injection into the trapezius muscle, intracisterna magna administration with the antiCX3CR1 neutralizing antibody was performed for 4 successive days after CFA or saline injection. Moreover, to assess the involvement of FKN in microglial activation of $\mathrm{Vc}$ and $\mathrm{C} 1-\mathrm{C} 2$, intra-cisterna magna administration with $\mathrm{FKN}$ was performed for 4 successive days in naive rats. On Day 4, the rat was anesthetized and fixed as described above.

Since extracellular signal-regulated kinase (ERK) phosphorylation in $\mathrm{Vc}$ and $\mathrm{C} 1-\mathrm{C} 2$ neurons following orofacial noxious stimulation is known to be a good marker for activation of nociceptive neurons, we studied the ERK phosphorylation in $\mathrm{Vc}$ and $\mathrm{C} 1-\mathrm{C} 2$ neurons (Noma et al., 2008). To assess the involvement of CX3CR1 in ERK phosphorylation in Vc and $\mathrm{C} 1-\mathrm{C} 2$ neurons following noxious mechanical stimulation to the facial skin ipsilateral to CFA or saline injection into trapezius muscle, intracisterna magna administration of the antiCX3CR1 neutralizing antibody was performed for 4 successive days after CFA or saline injection. On Day 4, the rat was perfused and fixed at $5 \mathrm{~min}$ after mechanical stimulation $(26 \mathrm{~g} ; 1$ $\mathrm{Hz}$; total, $5 \mathrm{~min}$ ) to the ipsilateral facial skin.

We also evaluated whether the facial skin inflammation affected phosphorylated ERK (pERK) expression in C2-C6 following noxious mechanical stimulation of the trapezius muscle or Ibal expression in the medullae and spinal cord. On Day 4 after CFA or saline injection into the facial skin, the rat was anesthetized and fixed at $5 \mathrm{~min}$ following noxious mechanical stimulation (100 g, by using the electronic von Frey anesthesiometer) of the trapezius muscle.

To clarify the distribution pattern of $\mathrm{Vc}$ and C1-C6 neurons activated by noxious stimulation to the facial skin or trapezius muscle, naive rats were perfused and fixed 5 min after capsaicin $(30 \mu \mathrm{l}, 1 \mathrm{~mm})$ injection into the facial skin or trapezius muscle, and pERK-IR cells were analyzed in Vc and C1-C6.

To assess the effect of major neck surgery on the $\mathrm{Vc}$ and $\mathrm{C} 1-\mathrm{C} 2$ neuronal activities, naive rats receiving noxious mechanical stimulation $(60 \mathrm{~g}, 5 \mathrm{~min})$ to the facial skin were perfused and fixed $5 \mathrm{~h}$ after exposing the $\mathrm{Vc}$ and $\mathrm{C} 1-\mathrm{C} 2$ recording areas, pERK immunohistochemical analysis was conducted in $\mathrm{Vc}$ and $\mathrm{C} 1-\mathrm{C} 2$ regions, and the number of pERK-IR cells was compared with that from naive rats without neck surgery.

Medullae and spinal cords were dissected out after perfusion and immersed in the same fixative for $1 \mathrm{~d}$ at $4^{\circ} \mathrm{C}$. Postfixed medullae were kept 
in 0.01 м PBS containing 20\% sucrose for overnight for cryoprotection. Ten-micrometer-thick tissue sections were cut with a freezing microtome (Leica), and every sixth section was collected in $0.01 \mathrm{M}$ PBS. Free-floating tissue sections were rinsed in $0.01 \mathrm{M}$ PBS and incubated in $10 \%$ normal goat serum (NGS) in PBS for $1 \mathrm{~h}$ at room temperature (RT), and then incubated in rabbit polyclonal Ibal antibody (1:2000; Wako) as marker of microglial cells or rabbit antiphospho-p44/42 mitogenactivated protein kinase (MAPK) antibody (1:1000; Cell Signaling Technology) for $72 \mathrm{~h}$ at $4^{\circ} \mathrm{C}$. The sections incubated in biotinylated goat anti-rabbit IgG (1:600; Vector Laboratories) for $2 \mathrm{~h}$ at RT. After being rinsed with $0.01 \mathrm{M}$ PBS, the sections were incubated in peroxidaseconjugated avidin-biotin complex (1:100; Vector Laboratories) for $1 \mathrm{~h}$ at RT. Then, the sections were washed in $0.05 \mathrm{M}$ Tris buffer (TB) and incubated in $0.035 \% 3.3^{\prime}$-daiminobenzidine tetrahydrochloride hydrate (Sigma-Aldrich), $0.2 \%$ nickel ammonium sulfate, and $0.05 \%$ peroxide in $0.05 \mathrm{~m} \mathrm{~TB}, \mathrm{pH} 7.4$, for $5 \mathrm{~min}$. The sections were then washed in PBS, serially mounted on gelatin-coated slides, dehydrated in a series of alcohols (from 50 to $100 \%$ ), and coverslipped.

Ibal expression was analyzed in a square grid $\left(26.7 \times 26.7 \mu \mathrm{m}^{2}\right)$ of $\mathrm{Vc}$ and C1-C2 that receives afferents from the second branch of the trigeminal nerve that supplies the lateral facial skin that was used for testing mechanical sensitivity, and in the area between $720 \mu \mathrm{m}$ rostral and $50,000 \mu \mathrm{m}$ caudal to the obex that contains the densest labeling of microglia. The area occupied by the Ibal immuno-products in Vc and C1-C2 was measured by using a computer-assisted imaging analysis system (ImageJ $1.37 \mathrm{v}$; NIH). We also performed immunohistochemical staining without primary antibody for Ibal for three sections in each group of rats, and no immune products could be observed (data not shown). To analyze the number of pERK-IR cells, the pERK-IR cells were drawn under a light microscope with an attached camera-lucida drawing tube (Neurolucida 2000; MicroBrightField). The number of pERK-IR cells in Vc and C1-C2 was counted from one section, and the mean number of pERK-IR cells was calculated from each animal. The processes to measure the area occupied by the Ibal immunoproducts and to count the number of pERK-IR cells were performed by an investigator blind to the experimental treatments.

\section{Double-labeling immunohistochemistry}

On Day 4 after CFA injection into trapezius muscle, the rat was anesthetized, transcardially perfused, and fixed as described in the previous section. The medullae were dissected out after perfusion and immersed in the same fixative for $4 \mathrm{~h}$ at $4^{\circ} \mathrm{C}$. The medullae were kept in $0.01 \mathrm{M}$ PBS containing $20 \%$ sucrose for $12 \mathrm{~h}$ for cryoprotection. The specimen was then embedded in TissueTek (Sakura Finetek) and stored until cryosectioning at $-20^{\circ} \mathrm{C}$. The sections were cut from $\mathrm{Vc}$ and $\mathrm{C} 1-\mathrm{C} 2$ on a cryostat at a thickness of $10 \mu \mathrm{m}$. The sections were thaw-mounted onto MAScoated Superfrost Plus microscope slides (Matsunami) and dried at RT overnight in a dark room.

Following the incubation with citrate buffer (Abcam) for $30 \mathrm{~min}$ and $3 \%$ NGS in $0.3 \%$ Triton $\mathrm{X}-100$ in PBS for $2 \mathrm{~h}$ at RT, the sections were incubated with rabbit polyclonal CX3CR1 antibody (1:100; Torrey Pines Biolabs) and mouse monoclonal Ibal antibody (1:100; Abcam), mouse monoclonal glial fibrillary acidic protein (GFAP) antibody (1:1000; Millipore Bioscience Research Reagents) or mouse monoclonal NeuN antibody (1:1000; Millipore Bioscience Research Reagents) in 0.01 м PBS containing $3 \% \mathrm{NGS}$ and $0.3 \%$ Triton X-100 overnight at $4^{\circ} \mathrm{C}$ to identify the localization of CX3CR1. After rinsing with $0.01 \mathrm{M}$ PBS, the sections were incubated in Alexa Fluor 488 anti-rabbit IgG (1:200; Invitrogen) and Alexa Fluor 568 anti-mouse IgG (1:200; Invitrogen) in 0.01 м PBS for $2 \mathrm{~h}$ at RT.

To identify the localization of phosphorylated p38 (pp38) in Vc and $\mathrm{C} 1-\mathrm{C} 2$, the sections were incubated with mouse monoclonal pp38 MAPK (Thr180/Tyr182) antibody (1:500; Cell Signaling Technology) and rabbit polyclonal CX3CR1 antibody (1:100), rabbit polyclonal GFAP antibody (1:1000; Dako), or rabbit Cy3-conjugated polyclonal NeuN antibody (1:100, Millipore) in 0.01 м PBS containing 3\% NGS and $0.3 \%$ Triton X-100 overnight at $4^{\circ} \mathrm{C}$. After rinsing, the sections were incubated in Alexa Fluor 488 anti-mouse IgG (1:200) and Alexa Fluor 568 antirabbit IgG (1:200) in $0.01 \mathrm{M}$ PBS for $2 \mathrm{~h}$ at RT.
To identify the localization of the IL- $1 \beta$ in Vc and C1-C2, the sections were incubated with mouse monoclonal Ibal antibody (1:100; Abcam) and rabbit polyclonal IL- $1 \beta$ antibody $(1: 100 ;$ Abcam) in $0.01 \mathrm{M}$ PBS containing $3 \%$ NGS and $0.3 \%$ Triton X-100 overnight at $4{ }^{\circ} \mathrm{C}$. Next, the sections were incubated in Alexa Fluor 488 anti-mouse $\operatorname{IgG}(1: 200)$ and Alexa Fluor 568 anti-rabbit IgG (1:200) in $0.01 \mathrm{~m}$ PBS for $2 \mathrm{~h}$ at RT.

To identify the localization of IL- $1 \beta$ receptor in Vc and C1-C2, IL-1RI. The sections were incubated with rabbit polyclonal IL-1RI antibody (1: 100; Santa Cruz Biotechnology) and mouse monoclonal NeuN antibody (1:1000) in 0.01 M PBS containing $3 \%$ NGS and $0.3 \%$ Triton X-100 overnight at $4^{\circ} \mathrm{C}$. After rinsing, the sections were incubated in Alexa Fluor 488 anti-rabbit IgG (1:200 in $0.01 \mathrm{~m} \mathrm{PBS})$ and Alexa Fluor 568 anti-mouse $\operatorname{IgG}(1: 200$ in $0.01 \mathrm{M}$ PBS) for $2 \mathrm{~h}$ at RT.

Five minutes after a $60 \mathrm{~g}$ mechanical stimulation $(1 \mathrm{~Hz}, 5 \mathrm{~min})$ to the lateral facial skin ipsilateral to the CFA injection, the rat was anesthetized and fixed, and the sections of $\mathrm{Vc}$ and $\mathrm{C} 1-\mathrm{C} 2$ were prepared as described above. To identify the localization of ERK phosphorylation in Vc and C1-C2, sections were incubated with mouse monoclonal p44/p42 MAPK (Thr202/Thr204) antibody (1:500; Cell Signaling Technology) and rabbit polyclonal Ibal antibody (1:100) or rabbit polyclonal Cy3-conjugated NeuN antibody $(1: 100)$ for $3 \mathrm{~d}$ at $4^{\circ} \mathrm{C}$. After rinsing, the sections were incubated in Alexa Fluor 488 anti-mouse $\operatorname{IgG}$ (1:200 in 0.01 м PBS) for $2 \mathrm{~h}$ at RT.

Following rinsing with $0.01 \mathrm{M}$ PBS, the sections were coverslipped in mounting medium (ThermoFisher Scientific), and doubleimmunolabeled cells were analyzed using a fluorescence microscope (Keyence) or a confocal microscope (Carl Zeiss).

\section{Western blotting analysis}

On Day 4 after CFA or saline injection into the trapezius muscle, the rat was anesthetized with sodium pentobarbital $(50 \mathrm{mg} / \mathrm{kg}$, i.p.) and perfused with saline. The medullae containing Vc and C1-C2 and facial skin were taken out and homogenized in ice-cold lysis buffer $(137 \mathrm{~mm} \mathrm{NaCl}$, 20 mm Tris-HCl, pH 8.0, 1\% NP40, 10\% glycerol, 1 mm phenylmethylsulfonyl fluoride, $10 \mu \mathrm{g} / \mathrm{ml}$ aprotinin, $1 \mathrm{~g} / \mathrm{ml}$ leupeptin, and $0.5 \mathrm{~mm}$ sodium vanadate) using a tube pestle (ThermoFisher Scientific). Samples were centrifuged at 15,000 rpm for $10 \mathrm{~min}$ at $4^{\circ} \mathrm{C}$. The supernatant was collected into new tubes, and the protein concentration of the sample was determined with a protein assay kit (Bio-Rad). The protein sample was heat denatured in Laemmli sample buffer solution (Bio-Rad). The sample $(30 \mu \mathrm{g})$ was subjected to electrophoresis for protein separation on $10 \%$ SDS-PAGE and electroblotted onto polyvinylidene difluoride membranes (Trans-Blot Turbo Transfer Pack; Bio-Rad) using TransBlot Turbo (Bio-Rad). Following rinsing with Tris-buffered saline containing $0.1 \%$ Tween 20 (TBST), the membrane was incubated with $3 \%$ bovine serum albumin (BSA; Bovogen). The membrane was incubated overnight at $4^{\circ} \mathrm{C}$ with anti-FKN antibody (1:500; R \& D Systems), antiCX3CR1 antibody (1:1000), anti-pp38 MAPK (Thr180/Tyr182) antibody (1:1000), anti-TNF- $\alpha$ antibody (1:500; R \& D Systems), anti-IL-6 antibody (1:100; R \& D Systems), anti-BDNF antibody (1:1000; Osenses), or anti-IL-1 $\beta$ antibody (1:1000) diluted in TBST containing $5 \%$ BSA. Each protein binding was visualized using a horseradish peroxidase-conjugated donkey anti-rabbit antibody (Cell Signaling Technology) and Western Lightning ELC Pro (PerikinElmer). Band intensity was quantified using a ChemiDoc MP system (Bio-Rad) and normalized to $\beta$-actin or p38 immunoreactivity on blots reprobed with anti- $\beta$-actin antibody (1:200; Santa Cruz Biotechnology) or anti-p38 antibody (1:200; Cell Signaling Technology) after removing protein binding using a stripping reagent (Thermo Scientific).

\section{Vc and C1-C2 neuronal recording}

On Day 4 after CFA injection into the trapezius muscle and the following 4 successive days of administration of anti-CX3CR1neutralizing antibody or anti-IL-1 $\beta$ neutralizing antibody, a single-neuron recording experiment was performed using electrophysiological procedures similar to those reported previously (Tsuboi et al., 2011). Briefly, the rat was anesthetized with sodium pentobarbital $(50 \mathrm{mg} / \mathrm{kg}$, i.p.), and the trachea and right femoral vein were cannulated to allow artificial respiration and intravenous administration of drugs. The anesthesia was maintained 


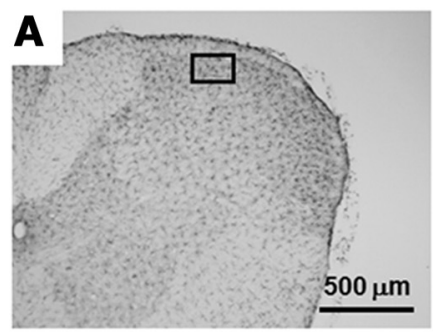

Day 4 CFA

E

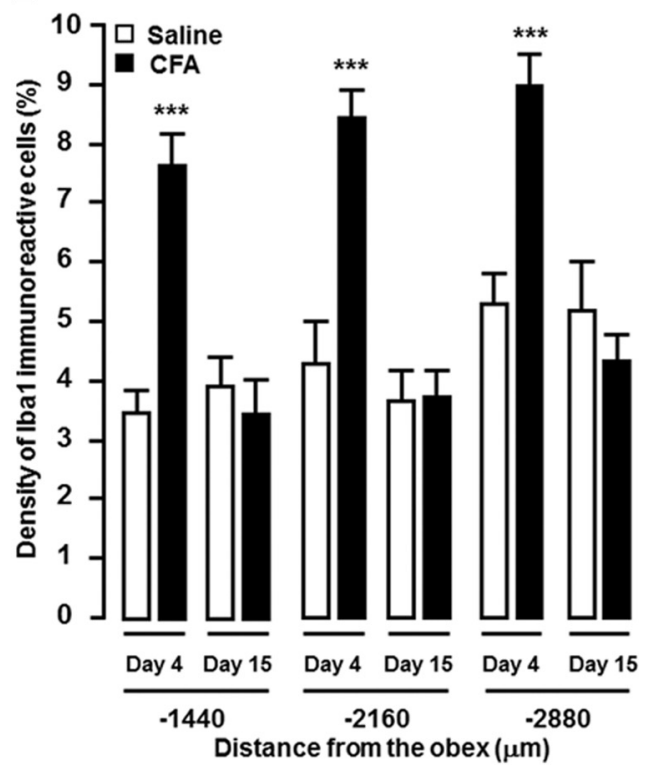

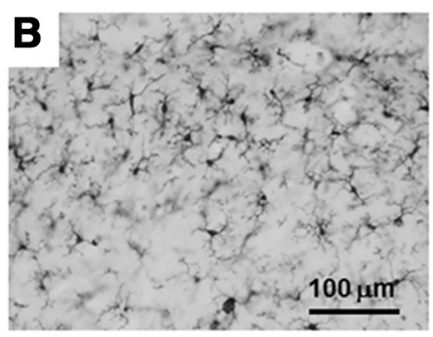

Day 4 CFA

$\mathbf{F}$

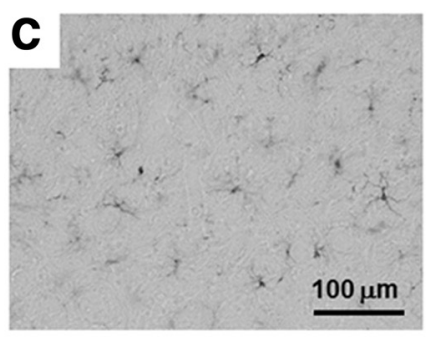

Day 4 Saline

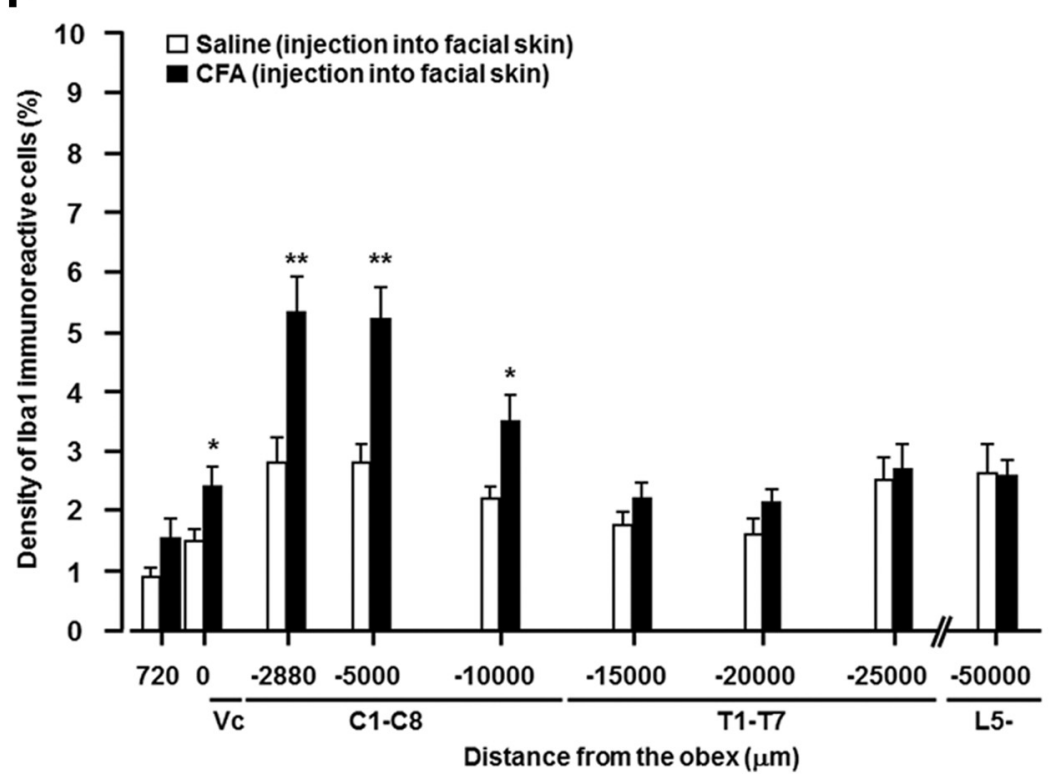

Figure 2. Iba1-IR cells in Vcand C1-C2 on Days 4 and 15 after saline or CFA injection into the trapezius muscle. $\boldsymbol{A}$, Photomicrograph of the Vc on Day 4 after CFA injection. B-D, High-magnification photomicrographs of Iba1-IR cells on Day 4 after CFA (B) or saline injection (C), and those on Day 15 after CFA injection (D). $\boldsymbol{E}$, The relative area occupied by the Iba1 immunoproducts in Vc and C1-C2 on Days 4 and 15 after CFA or saline injection. ${ }^{* *} p<0.001$ (compared to saline-injected animals; $n=10$ or 11 in each group; one-way ANOVA followed by Bonferroni's multiple-comparison tests). $\boldsymbol{F}$, Changes in the relative area occupied by the Iba1 immunoproducts in the medullae and spinal cord on Day 4 after CFA or saline injection into the facial skin. ${ }^{*} p<0.05 ;{ }^{* *} p<0.01$ (compared to saline-injected animals; $n=10$ or 11 in each group; Student's $t$ test).

with isoflurane (2-3\%) mixed with oxygen during surgery. The rat was mounted in a stereotaxic frame, the medullae were exposed by a laminectomy, and dura and pia mater were removed from the exposed brain surface. The rat was immobilized with pancuronium bromide $(0.6 \mathrm{mg} /$ kg, i.v.; Schering-Plough) and artificially ventilated. End-tidal $\mathrm{CO}_{2}$ was maintained at 3.5 to $4.5 \%$ and the rectal temperature at $37^{\circ} \mathrm{C}$ by a feedback-controlled heating blanket (Nihon Koden). The electrocardiogram was monitored, and the heart rate was maintained at $250-300 / \mathrm{min}$. A laminectomy was performed to expose $\mathrm{Vc}$ and $\mathrm{C} 1-\mathrm{C} 2$, a pool was made with skin flaps around the laminectomy, and the brainstem kept moist with vehicle solution (isotonic saline). Single neuronal activity was recorded using tungsten microelectrodes (impedance, $13 \mathrm{M} \Omega ; 1000 \mathrm{~Hz}$; FHC) from histologically determined sites in Vc and C1-C2. Each neuron was functionally identified as a wide dynamic range (WDR) neuron or a nociceptive-specific neuron on the basis of their responses to innocuous or noxious mechanical stimulation to the lateral facial skin ipsilateral to the CFA injection into trapezius muscle, as described previously (Iwata et al., 2001). WDR neurons responding to innocuous stimulation and, to a greater degree, noxious stimulation of the lateral facial skin were analyzed in this study. This single neuronal activity was amplified using a differential amplifier (Nihon Koden) and stored in the microcomputer hard disk. Spikes were sorted, and spike frequencies were analyzed using the Spike II software (CED 1401). After the identification of a WDR neuron, mechanical stimuli were applied to the facial skin following the recording of the neuron's background activity for 30 s. For low-intensity mechanical stimulation of the neuronal mechanoreceptive field, graded stimuli with von Frey filaments (1, 6, 15, 26, and $60 \mathrm{~g})$ and brushing with a nylon hair brush were applied for $5 \mathrm{~s}$ at $10 \mathrm{~s}$ intervals. High-intensity ( pinch) stimulation with pinch produced by a small arterial clip was also applied for $1 \mathrm{~min}$. After neuronal recording, the recording sites in $\mathrm{Vc}$ and C1-C2 were identified histologically.

\section{Statistical analysis}

Data are expressed as means \pm SEM or median (25 to $75 \%$ interquartile range). Statistical analyses were performed by Student's $t$ test, MannWhitney $U$ test, one-way ANOVA followed by Dunnett's, Tukey's, Newman-Keuls, or Bonferroni's multiple-comparison tests, or two-way repeated-measures ANOVA followed by Bonferroni's multiplecomparison tests where appropriate. A value of $p<0.05$ was considered significant.

\section{Results}

Changes in mechanical sensitivity following CFA injection We first studied the changes in the HWT to mechanical stimulation of the lateral facial skin after CFA injection into the trapezius muscle. The mechanical HWT significantly decreased after CFA injection into the trapezius muscle $(17.2 \pm 4.0 \mathrm{~g})$ compared with saline-injected controls $(38.2 \pm 2.3 \mathrm{~g}$ ) on Day 4 (Fig. $1 \mathrm{Aa})$. Mechanical allodynia was observed in the ipsilateral facial skin on Day 4 through Day $7(p<0.05)$. There were no significant changes in mechanical HWT to the facial skin stimulation ipsilateral to the saline-injected trapezius muscle during the experimental period. On Day 4, there were no significant differences in 
the duration and the number of approaches to the water tap between CFAand saline-injected rats, indicating that the inflammation of trapezius muscle did not alter the animals' head movement (Fig. $1 A b, A c$ ). No inflammation was observed in the facial skin before and on Days 1, 4, and 15 after CFA injection into the trapezius muscle, although the trapezius muscle was inflamed with a dramatic tissue infiltration of inflammatory cells on Days 1 and 4 (Fig. $1 B-I$ ).

Next, we studied the changes in the mechanical sensitivity of the trapezius muscle after CFA injection into the facial skin. The BWT to mechanical stimulation with von Frey filaments applied to the trapezius muscle was significantly decreased after CFA injection into the facial skin $(22.7 \pm 4.9 \mathrm{~g})$ compared with salineinjected controls $(50.0 \pm 3.1 \mathrm{~g})$ on Day 4 (Fig. 1J). The BWT to mechanical stimulation (by applying the electronic von Frey anesthesiometer) of the trapezius muscle significantly decreased after CFA injection into the facial skin $(100.3 \pm 5.6 \mathrm{~g})$ compared with saline-injected controls $(158.2 \pm 13.2 \mathrm{~g}$ ) on Day 4 (Fig. $1 K$ ). There were no significant changes in the BWT to the trapezius muscle stimulation ipsilateral to the saline-injected facial skin.

The number of pERK-IR cells in C2-C6 following noxious mechanical stimulation of the trapezius muscle was significantly higher on Day 4 after CFA injection into the facial skin compared with saline-injected rats (Fig. $1 L$ ). No inflammation was observed in the trapezius muscle on Day 4 after CFA injection into the facial skin, although the facial skin was inflamed (Fig. $1 M, N$ ).

After capsaicin injection into the facial skin or trapezius muscle, pERK-IR cells were obvious at 2880 or $7290 \mu \mathrm{m}$ caudal to the obex, respectively (Fig. 1O). Although pERK-IR cells were distributed widely in $\mathrm{Vc}$ and $\mathrm{C} 1-\mathrm{C} 6$, rarely was there any evidence of considerable distribution overlap in the pERK-IR cells after capsaicin injection into the facial skin or trapezius muscle. Animals ate and gained weight normally during the experimental period. Since there is no significant difference in mechanical sensitivity between sham and CFA-injected rats on Day 1 after injection, we further studied the trapezius muscle-inflamed rats $4 \mathrm{~d}$ after CFA injection.

\section{Microglial activation in Vc and C1-C2}

On Day 4 after CFA injection into the trapezius muscle, microglia showing Iba1 immunoreactivity had a large soma with thick processes, which is evidence of hyperactivity (Fig. 2A,B). Microglia showed no large soma with thick processes on Day 4 after saline injection and on Day 15 after CFA injection (Fig. 2C,D). The area occupied by the Iba1-IR cells on Day 4 after CFA injection was much larger than that observed in saline-injected rats at $1440 \mu \mathrm{m}$ $(\mathrm{Vc})$ and $2880 \mu \mathrm{m}(\mathrm{C} 1-\mathrm{C} 2)$ caudal to the obex $(1440 \mu \mathrm{m}, \mathrm{CFA}$, $7.5 \pm 0.4 \%$; saline, $3.8 \pm 0.3 \% ; 2160 \mu \mathrm{m}$, CFA, $8.3 \pm 0.3 \%$; saline, $4.3 \pm 0.7 \%$; $2880 \mu \mathrm{m}$, CFA, $9.1 \pm 0.6 \%$; saline, $5.3 \pm$ $0.5 \%$; Fig. $2 E$ ). There were no significant differences in mean areas occupied by Iba1-IR cells between CFA- and saline-injected rats on Day 15.
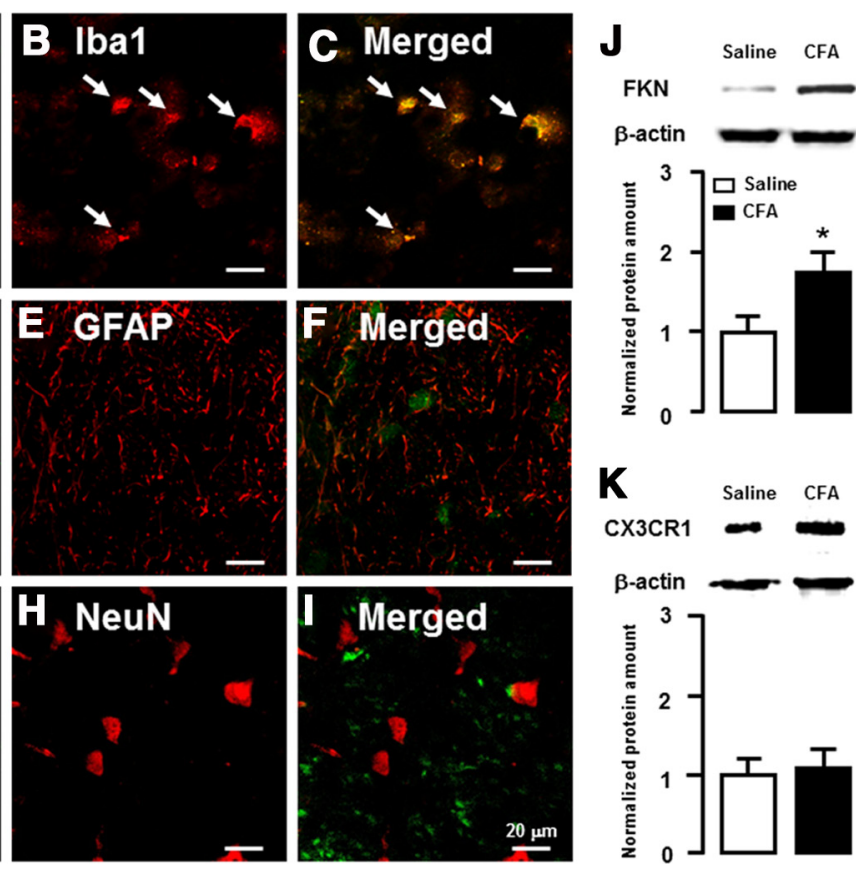

Figure 3. $A-I$, Photomicrographs of CX3CR1-IR cells $(\boldsymbol{A}, \boldsymbol{D}, \boldsymbol{G})$, Iba1-IR cells $(\boldsymbol{B})$, CX3CR1-IR and Iba1-IR cells $(\boldsymbol{C})$, GFAP-IR cells $(\boldsymbol{E})$, CX3CR1-IR and GFAP-IR cells $(\boldsymbol{F})$, NeuN-IR cells $(\boldsymbol{H})$, and CX3CR1-IR and NeuN-IR cells $(\boldsymbol{I})$ in Vc and C1-C2 on Day 4 after CFA injection. The arrows indicate double-IR cells. $\boldsymbol{J}, \boldsymbol{K}$, Normalized amount of FKN $(\boldsymbol{J})$ and $C X 3 \mathrm{CR} 1(\boldsymbol{K})$ protein in Vc and $(1-C 2$ on Day 4 after CFA or saline injection. $\beta$-actin was used as a loading control. ${ }^{*} p<0.05$ ( $n=16$ in saline-injected rats; $n=15$ in (FA-injected rats; Student's $t$ test).

Microglia showing Ibal immunoreactivity also had a large soma with thick processes in Vc and C1-C2 on Day 4 after the CFA injection into the facial skin. The area occupied by the Iba1-IR cells on Day 4 after CFA injection was much larger than that observed in saline-injected rats between the obex and 10,000 $\mu \mathrm{m}$ caudal to the obex (Fig. $2 F$ ).

\section{FKN and its receptor expression in $\mathrm{Vc}$ and $\mathrm{C} 1-\mathrm{C} 2$}

To examine the localization of CX3CR1 in Vc and C1-C2 on Day 4 after the CFA injection into the trapezius muscle, immunohistochemical analysis for CX3CR1, Iba1, GFAP, or NeuN was performed. CX3CR1 was expressed in Iba1-IR cells but not in GFAP-IR or NeuN-IR cells (Fig. $3 A-I$ ). Changes in FKN and CX3CR1 protein expression in Vc and C1-C2 on Day 4 after CFA injection was also examined. FKN protein expression in $\mathrm{Vc}$ and $\mathrm{C} 1-\mathrm{C} 2$ ipsilateral to the CFA injection was significantly greater than that in the saline-injected group (saline, $1.0 \pm 0.1$; CFA, $1.8 \pm 0.2 ; p<0.05 ;$ Fig. $3 J$ ). There was no significant difference in CX3CR1 protein expression between saline- and CFA-injected rats (Fig. $3 K$ ).

\section{Effect of FKN signaling on microglial activation and} mechanical sensitivity

After daily intra-cisterna magna anti-CX3CR1 neutralizing antibody administration (Day 0 through Day 4), Iba1-IR cells in Vc showed no large soma with thick processes on Day 4 after CFA injection, although Iba1-IR cells showed histological changes in CFA-injected rats with intra-cisterna magna saline administration (Fig. $4 A-C$ ). The increase in the area occupied by the Iba1-IR cells in Vc and C1-C2 at 1440, 2160, and $2880 \mu \mathrm{m}$ caudal to the obex on Day 4 after CFA injection was significantly prevented by the daily intra-cisterna magna anti-CX3CR1 neutralizing antibody administration (Fig. 4D). There were no significant differences in mean areas occupied by Iba1-IR cells between 


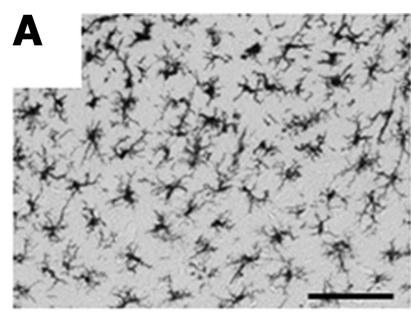

CFA / i.c.m. Saline

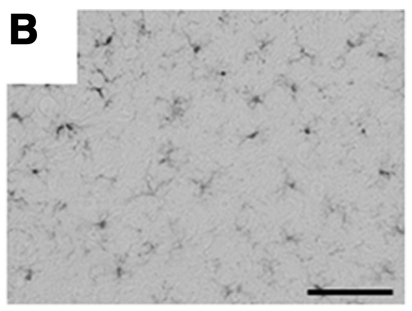

CFA / i.c.m. anti-CX3CR1

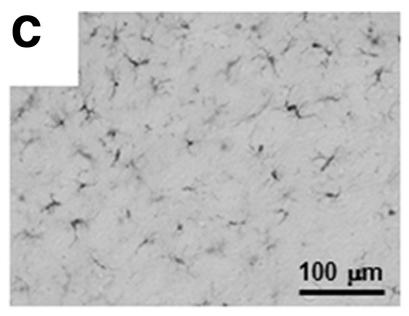

Saline / i.c.m. Saline

\section{D}
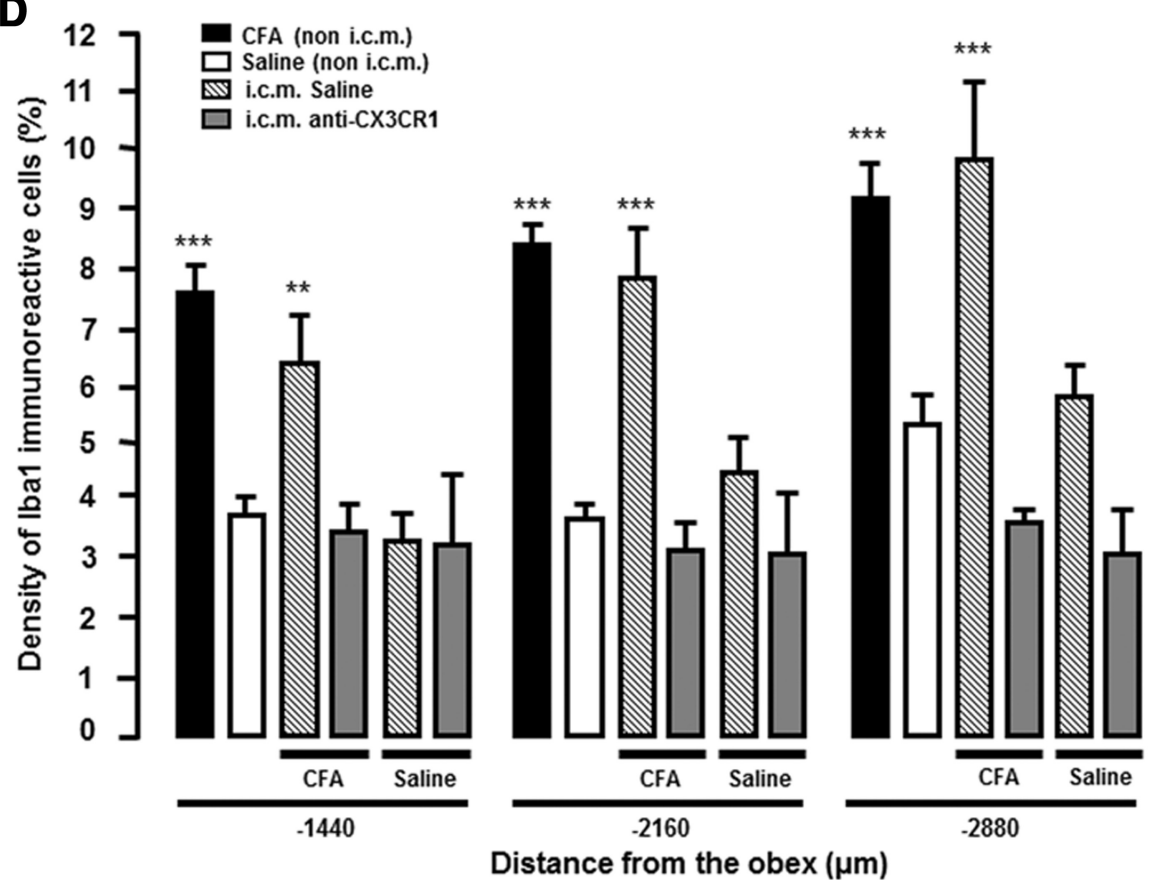

E
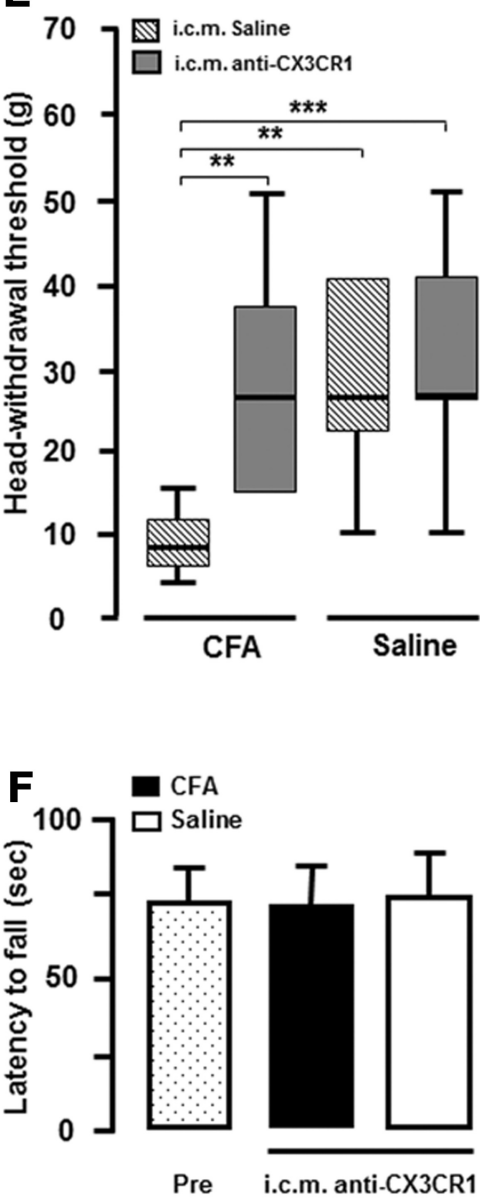

Figure 4. $\quad A, B$, Photomicrographs of Iba1-IR cells on Day 4 after CFA injection into the trapezius muscle with intra-cisterna magna saline $(\boldsymbol{A})$ or intra-cisterna magna anti-CXCR1 neutralizing antibody $(\boldsymbol{B})$ administration. $\boldsymbol{C}$, Photomicrograph of Iba1-IR cells on Day 4 after saline injection into the trapezius muscle with intra-cisterna magna saline administration. $\boldsymbol{D}$, Changes in the relative area occupied by the Iba1 immunoproducts in Vc and C1-C2 on Day 4 after saline or CFA injection with intra-cisterna magna saline or intra-cisterna magna anti-CXCR1 neutralizing antibody administration. ${ }^{* *} p<0.01 ;{ }^{* * *} p<0.001$ ( $n=9$ in CFA-injected rats; $n=8$ in saline-injected rats; $n=6$ in CFA-injected rats with intra-cisterna magna saline administration; $n=6$ in CFA-injected rats with intra-cisterna magna anti-CX3CR1 administration; $n=11$ in saline-injected rats with intra-cisterna magna saline administration; $n=5$ in saline-injected rats with intra-cisterna magna anti-CX3CR1 administration; one-way ANOVA followed by Bonferroni's multiple-comparison tests). $\boldsymbol{E}$, Changes in mechanical sensitivity measured in facial skin on Day 4 after CFA or saline injection into the ipsilateral trapezius muscle with intra-cisterna magna saline or anti-CXCR1 neutralizing antibody administration. ${ }^{* *} p<0.01$; ${ }^{* * *} p<0.001$ ( $n=11$ in CFA-injected rats with intra-cisterna magna saline administration; $n=12$ in CFA-injected rats with intra-cisterna magna anti-CX3CR1 administration; $n=11$ in saline-injected rats with intra-cisterna magna saline administration; $n=10$ in saline-injected rats with intra-cisterna magna anti-CX3CR1 administration; one-way ANOVA followed by a Kruskal-Wallis test). $\boldsymbol{F}$, Motor performance of CFA- or saline-injected rats with intra-cisterna magna anti-CXCR1 neutralizing antibody administration was evaluated using the Rota-Rod test. No motor deficits induced by intra-cisterna magna anti-CXCR1 neutralizing antibody administration were observed in CFA- or saline-injected rats ( $n=10$ in each).

anti-CX3CR1 neutralizing antibody administration and saline administration in saline-injected rats.

The decrease of the HWT on Day 4 after CFA injection was completely blocked by daily intra-cisterna magna antiCX3CR1 neutralizing antibody administration (Day 0 through Day 4) (Fig. 4E). Moreover, daily intra-cisterna magna antiCX3CR1 neutralizing antibody alone had no effect in salineinjected rats. Motor deficits or sedation were not observed on Day 4 in CFA-injected and saline-injected rats with daily intra-cisterna magna anti-CX3CR1 neutralizing antibody administration (Fig. $4 F$ ).

The HWT to mechanical stimulation of the facial skin was significantly shortened following $4 \mathrm{~d}$ successive intra-cisterna magna FKN administration compared with saline administration $(p<0.01$; Fig. 5A). Moreover, Iba1-IR cells in Vc and C1-C2 showed large soma with thick processes following $4 \mathrm{~d}$ successive intra-cisterna magna FKN administration (Fig. $5 B, C$ ). The suc- cessive intra-cisterna magna FKN administration also increased the area occupied by the Iba1-IR cells in Vc and C1-C2 at 1440, 2160 , and $2880 \mu \mathrm{m}$ caudal to the obex (Fig. 5D).

p38 phosphorylation in activated microglia and released molecules

To examine localization and expression of $\mathrm{p} 38$ phosphorylation in Vc and C1-C2 on Day 4 after CFA injection, immunohistochemical analysis for pp38 with CX3CR1, GFAP, or NeuN was performed. pp38 was expressed in CX3CR1-IR cells, but not in GFAP-IR or NeuN-IR cells (Fig. $6 A-I$ ). pp38 protein expression was significantly increased in Vc and C1-C2 on Day 4 after CFA injection compared with saline injection (saline, $1.0 \pm 0.1$; CFA, $1.6 \pm 0.3 ; p<0.05$; Fig. $6 J)$.

On Day 4 after CFA injection, the protein expression of TNF- $\alpha$, IL-6, BDNF, or IL- $1 \beta$ in Vc and C1-C2 was assessed by Western blotting of protein extracts (Fig. $7 A-D$ ). IL-1 $\beta$ protein 
expression in Vc and C1-C2 ipsilateral to CFA injection was significantly greater than that of the saline-injected group (saline, $1.0 \pm 0.2$; CFA, $2.3 \pm 0.4 ; p<0.01)$. No significant changes in TNF- $\alpha$, IL- 6 , and BDNF protein expression were observed between CFA- and saline-injected rats.

Immunohistochemical analysis for IL$1 \beta$, Iba1, IL- $1 \beta$ receptor, or NeuN was performed to examine localization of $\mathrm{IL}-1 \beta$ and its receptor in $\mathrm{Vc}$ and $\mathrm{C} 1-\mathrm{C} 2$ on Day 4 after CFA injection. IL- $1 \beta$ was expressed in Iba1-IR cells, and IL- $1 \beta$ receptor was expressed in NeuN-IR cells (Fig. $7 E-J)$. Decrease of the HWT on Day 4 after CFA injection was completely blocked by daily intra-cisterna magna anti-IL- $1 \beta$ neutralizing antibody administration (Day 0 through Day 4; Fig. $7 K)$.

Changes in pERK expression and Vc and C1-C2 WDR neuronal activity Immunohistochemical analysis for pERK with Ibal or NeuN was performed to analyze the distribution of activated neurons in Vc and C1-C2. pERK colocalized with NeuN-IR in Vc and C1-C2 cells following noxious mechanical stimulation of the lateral facial skin on Day 4 after CFA injection, indicating that the pERK-IR cells were neurons in $\mathrm{Vc}$ and $\mathrm{C} 1-\mathrm{C} 2$ (arrows in Fig. 8A-H). Many pERK-IR cells could be observed in the superficial laminae of Vc and $\mathrm{C} 1-\mathrm{C} 2$ following noxious mechanical stimulation of the facial skin in CFAinjected rats, whereas daily intra-cisterna magna anti-CX3CR1 neutralizing antibody administration (Day 0 through Day 4) reduced their number (Fig. 8I-K). On Day 4 after CFA injection, the numbers of pERK-IR cells in Vc and C1-C2 at 1440 and $2880 \mu \mathrm{m}$ caudal to the obex were significantly higher in the CFA-injected rats on the side ipsilateral to injection compared with those of saline-injected rats following noxious mechanical stimulation of the lateral facial skin (Fig. $8 \mathrm{~L}$ ). The mean number of pERK-IR cells in Vc and C1-C2 following noxious mechanical stimulation of the facial skin was significantly depressed following daily intra-cisterna magna administration of anti-CX3CR1 neutralizing antibody on Day 4 after CFA injection, indicating that anti-CX3CR1 neutralizing antibody significantly affected ERK phosphorylation in Vc and C1-C2 neurons (1440 $\mu \mathrm{m}$, i.c.m., saline, $21.4 \pm$ 1.8; anti-CX3CR1, $11.4 \pm 3.6 ; 2160 \mu \mathrm{m}$, i.c.m., saline, $65.6 \pm 1.8$; anti-CX3CR1, $32.2 \pm 10.5 ; 2880 \mu \mathrm{m}$, i.c.m., saline, $76.4 \pm 6.6$; anti-CX3CR1, $28.2 \pm 3.4$ ).

The effects of CFA injection into the trapezius muscle and the effects of intra-cisterna magna administration of anti-CX3CR1 in each; Student's $t$ test).
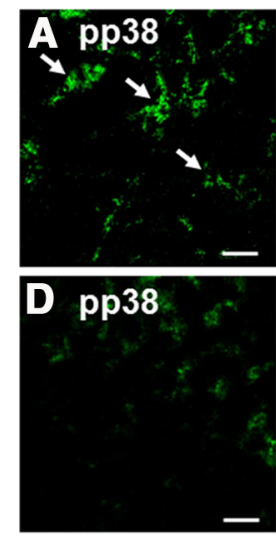
Student's $t$ test).

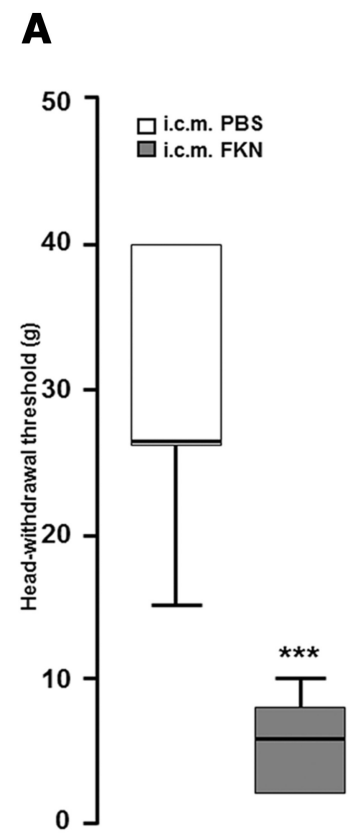

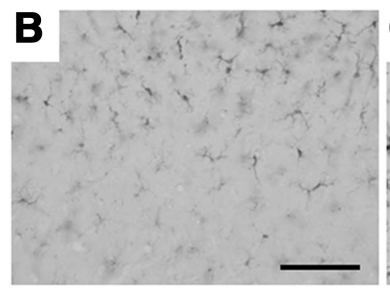

i.c.m. PBS

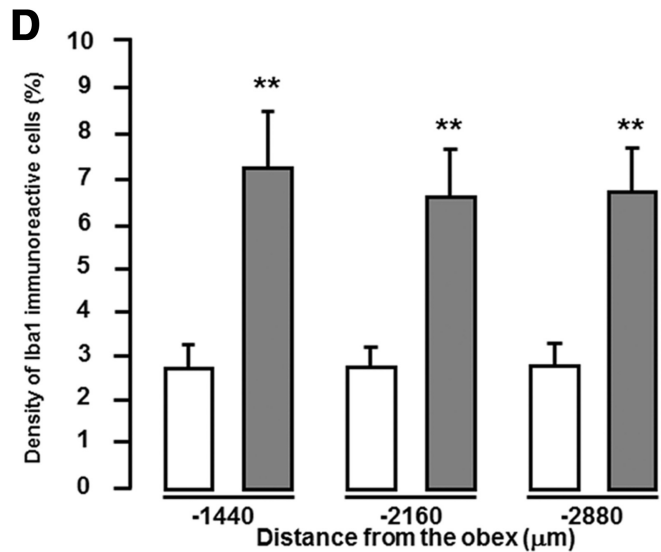

Figure 5. $A$, Changes in mechanical sensitivity of facial skin on Day 4 following successive intra-cisterna magna administration of FKN or 0.01 м PBS. ${ }^{* * *} p<0.001$ ( $n=9$ in each; Mann-Whitney $U$ test). $\boldsymbol{B}$, C, Photomicrographs of Iba1-IR cells on Day 4 after successive intra-cisterna magna $0.01 \mathrm{~m}$ PBS $(\boldsymbol{B})$ or FKN $(\boldsymbol{C})$ administration. $\boldsymbol{D}$, Changes in the relative area occupied by the Iba1 immunoproducts in Vc and C1-C2 on Day 4 after successive intra-cisterna magna PBS or FKN administration. ${ }^{* *} p<0.01(n=9$
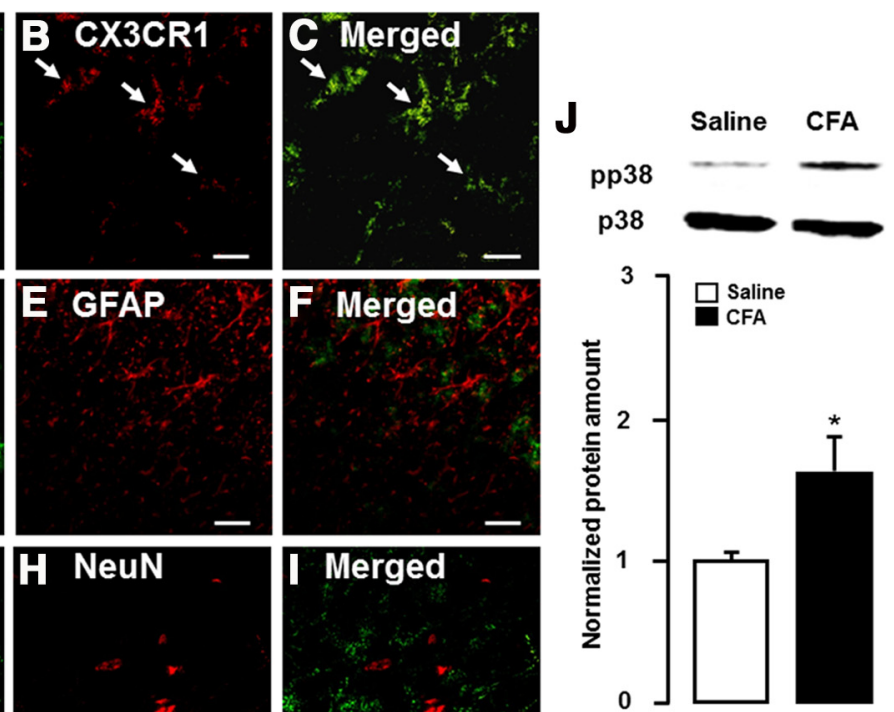

Figure 6. $\quad \boldsymbol{A}-I$, Photomicrographs of pp38-IR cells $(\boldsymbol{A}, \boldsymbol{D}, \boldsymbol{G}), \mathrm{CX} 3 \mathrm{CR} 1-\mathrm{IR}$ cells $(\boldsymbol{B})$, pp38-IR and CX3CR1-IR cells ( $\boldsymbol{C}$, GFAP-IR cells $(\boldsymbol{E})$, pp38-IR and GFAP-IR cells $(\boldsymbol{F})$, NeuN-IR cells $(\boldsymbol{H})$, and pp38-IR and NeuN-IR cells $(\boldsymbol{I})$ in Vc and C1-C2 on Day 4 after CFA injection. The arrows indicate double-IR cells. J, Normalized amount of pp38 protein in Vc and C1-C2 on Day 4 after CFA or saline injection. p38 protein was used as a loading control. ${ }^{*} p<0.05$ ( $n=21$ in saline-injected rats; $n=20$ in CFA-injected rats;
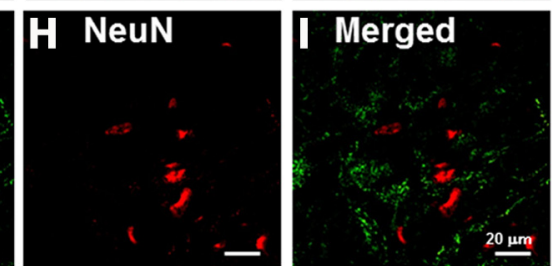

neutralizing antibody on WDR neuronal activity were also tested on Day 4 after CFA injection. A total of 37 WDR neurons was recorded from Vc and $\mathrm{C} 1-\mathrm{C} 2$ in CFA-injected rats with intracisterna magna saline $(n=5)$ and anti-CX3CR1 neutralizing antibody administration $(n=6)$, and those from saline-injected 

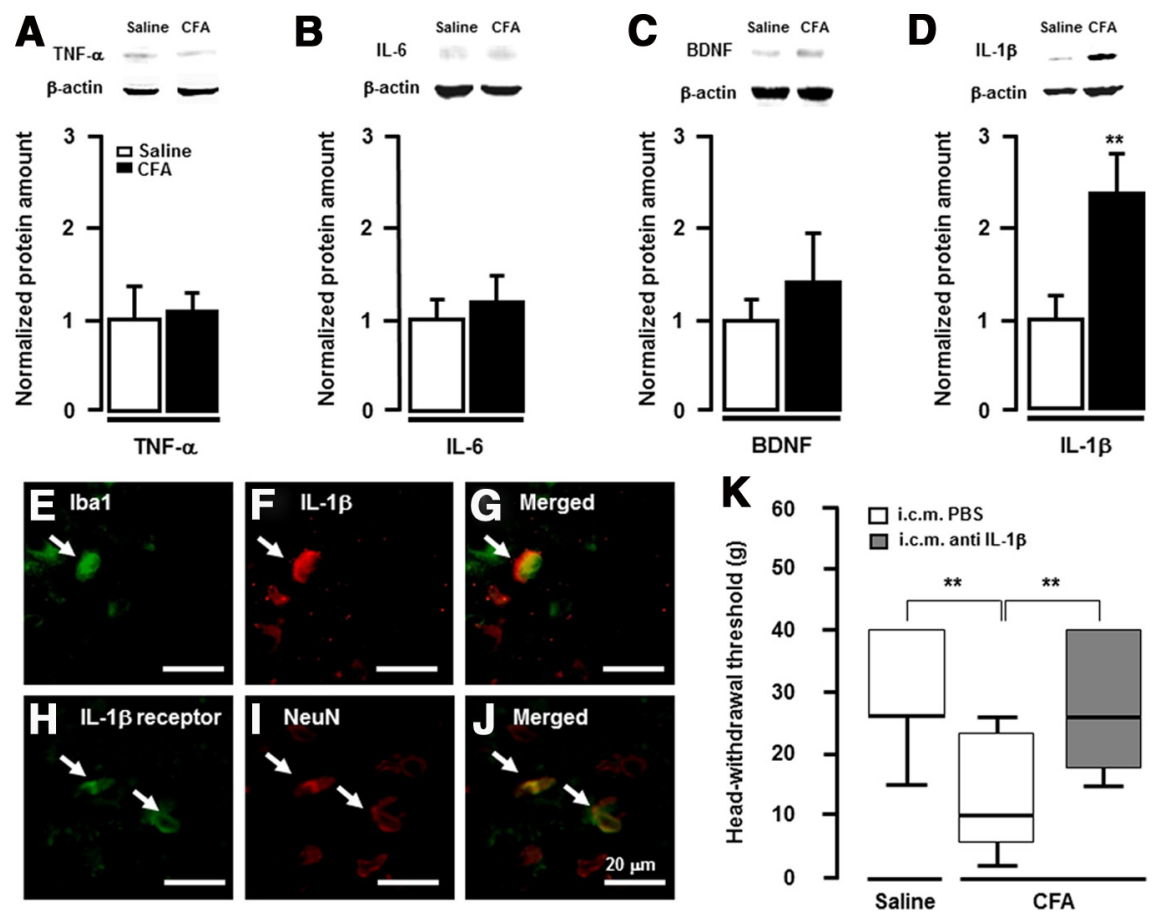

Figure 7. $\quad \boldsymbol{A}-\boldsymbol{D}$, Normalized amount of TNF- $\alpha(\boldsymbol{A}), \mathrm{IL}-6(\boldsymbol{B}), \operatorname{BDNF}(\boldsymbol{C})$, and IL- $1 \beta(\boldsymbol{D})$ protein in Vc and C1-C2 on Day 4 after CFA or saline injection. $\beta$-actin was used as a loading control. ${ }^{* *} p<0.01$ (TNF $\alpha, n=6$ in each; IL-6, BDNF, and IL-1 $\beta, n=10$ in each; Student's $t$ test). Error bars indicate SEM. $E$-J, Photomicrographs of Iba1-IR cells $(\boldsymbol{E})$, IL-1 $\beta$-IR cells $(\boldsymbol{F})$, Iba1-IR and IL-1 $\beta$-IR cells $(\boldsymbol{G})$, IL-1 $\beta$ receptor-IR cells $(\boldsymbol{H})$, NeuN-IR cells $(\boldsymbol{I})$, and IL-1 $\beta$ receptor-IR and NeuN-IR cells $(\boldsymbol{J})$ in Vc and $(1-C 2$ on Day 4 after CFA injection. The arrows indicate double-IR cells. $K$, Changes in mechanical sensitivity measured in facial skin on Day 4 after saline or CFA injection with intra-cisterna magna PBS or anti-IL-1 $\beta$ neutralizing antibody administration. ${ }^{* *} p<0.01(n=7$ in salineinjected with intra-cisterna magna PBS; $n=8$ in (FA-injected with intra-cisterna magna PBS or anti-IL-1 $\beta$; one-way ANOVA followed by Kruskal-Wallis test).

rats with intra-cisterna magna saline administration $(n=5)$. Typical mechanical-evoked responses of Vc and C1-C2 WDR neurons are demonstrated in Figure 9A. Mechanical-evoked responses of $\mathrm{Vc}$ and $\mathrm{C} 1-\mathrm{C} 2 \mathrm{WDR}$ neurons were enhanced in CFAinjected rats and were depressed after intra-cisterna magna administration of anti-CX3CR1 neutralizing antibody. All WDR neurons in saline- and CFA-injected rats increased in their firing frequency following increase in mechanical stimulus intensities $(1,6,15,26$, and $60 \mathrm{~g})$. On Day 4 after CFA injection, intracisterna magna administration of anti-CX3CR1 neutralizing antibody significantly depressed mechanical-evoked responses of WDR neurons compared with the intra-cisterna magna administered saline group (Fig. 9B). We could not observe any changes in background activity following intra-cisterna magna administration of anti-CX3CR1 neutralizing antibody in CFA-injected rats (Fig. 9C). Furthermore, brush- and pinch-evoked responses were significantly smaller in the intra-cisterna magna administered anti-CX3CR1 neutralizing antibody group compared with the intra-cisterna magna administered saline group in the CFAinjected rats (brush, i.c.m., saline, $19.2 \pm 3.9$; anti-CX3CR1, $8.0 \pm 1.2$; pinch, i.c.m., saline, $75.4 \pm 14.6$; anti-CX3CR1, $35.9 \pm$ 5.4; Fig. 10D). All recorded WDR neurons were located in the superficial laminae of the Vc and C1-C2 (Fig. 9E).

No significant changes in IL- $1 \beta$ protein expression in the facial skin was observed following CFA injection into the trapezius muscle, suggesting that IL- $1 \beta$ was not affecting peripheral neurons in this model (Fig. 10A). Therefore, the effect of intra-cisterna magna administration of anti-IL- $1 \beta$ neutralizing antibody on WDR neuronal activity was tested on Day 4 after CFA injection. A total of 45 WDR
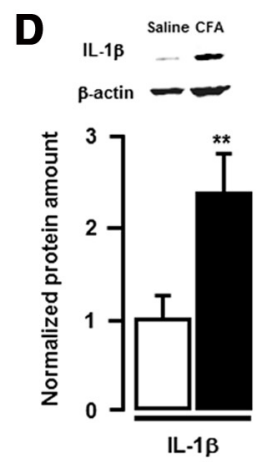

neurons was recorded from the $\mathrm{Vc}$ and $\mathrm{C} 1-\mathrm{C} 2$ in CFA-injected rats with intracisterna magna PBS $(n=15)$ or anti-IL-1 $\beta$ neutralizing antibody administration $(n=$ 15 ), and those from saline-injected rats with intra-cisterna magna PBS administration $(n=15)$. All WDR neurons in saline- and CFA-injected rats increased in their firing frequencies as mechanical stimulus intensity was increased, and mechanical-evoked responses of those neurons were enhanced in CFA-injected rats and were depressed in the rats with intra-cisterna magna administration of anti-IL- $1 \beta$ neutralizing antibody (Fig. 10B). We could not observe any changes in the background activity of each neuron (Fig. 10C). Furthermore, brushand pinch-evoked responses were significantly smaller in the anti-IL- $1 \beta$ neutralizing antibody-administered group compared with the PBS-administered group in CFAinjected rats (brush, PBS, i.c.m., saline injected, $7.1 \pm 1.4$; CFA injected, $23.4 \pm 2.7$; anti-IL-1 $\beta$, i.c.m., CFA injected, $11.4 \pm 1.6$; pinch; PBS, i.c.m., saline injected, $34.7 \pm$ 4.6; CFA injected, $58.2 \pm 6.1$; anti-IL- $1 \beta$, i.c.m., CFA injected, $34.2 \pm 3.6$; Fig. 10D). All WDR neurons were located in the superficial laminae of the Vc and $\mathrm{C} 1-\mathrm{C} 2$ (Fig. $10 E)$. No significant differences in the number of pERK-IR cells in Vc and C1-C2 following noxious mechanical stimulation of the facial skin between rats with neck surgery and rats without neck surgery, indicating that major neck surgery itself does not affect neuronal activities (Fig. $10 F-H$ ).

In this experiment, there were no $\mathrm{Vc}$ and $\mathrm{C} 1-\mathrm{C} 2 \mathrm{WDR}$ neurons responding to mechanical stimulation of both the facial skin and trapezius muscle.

\section{Discussion}

Some animal models have been developed to evaluate mechanical and heat hypersensitivity associated with orofacial inflammation (Shinoda et al., 2005; Honda et al., 2008). Previously, we established an animal model in which ectopic inflammatory pain can be induced in the noninflamed adjacent division of the trigeminal nerve following local inflammation in the orofacial region (Shinoda et al., 2011). However, orofacial ectopic pain model accompanied by local inflammation in the neck muscle has not been studied. In this study, rats with local inflammation in the trapezius muscle demonstrated mechanical allodynia in the facial skin. Mechanical allodynia of the trapezius muscle was also induced following facial skin inflammation, indicating that mechanical allodynia in one body region can be induced by local inflammation in an area remote from this region. The development of such an animal model for ectopic spread of manifestation of mechanical hypersensitivity can also be used to increase knowledge the mechanisms underlying ectopic orofacial pain associated with remote local inflammation.

In the dorsal horn, FKN is shed via the protease CatS from the neuronal cell membrane, and the soluble FKN acts as a chemoattractant (Savarin-Vuaillat and Ransohoff, 2007; Clark et al., 2009). Under neuropathic pain conditions, although FKN im- 
munoreactivity and its mRNA levels in the spinal cord are not altered (Verge et al., 2004), CX3CR1 expression in microglia may be upregulated (Lindia et al., 2005). In some inflammatory pain models, CX3CR1 protein expression is known to be upregulated and mature FKN protein is also increased in the spinal cord (Sharma et al., 2008; Staniland et al., 2010). IL- $1 \beta$, IL-6, and TNF- $\alpha$ protein expressions are also increased in the lumbar spinal cord following intraplantar administration of CFA (Raghavendra et al., 2004), and IL-6 is involved in the expression of microglial CX3CR1 in the spinal cord (Lee et al., 2010). In this study, the lack of changes in IL-6 protein expression in $\mathrm{Vc}$ and $\mathrm{C} 1-\mathrm{C} 2$ in CFA-injected rats may explain why the microglial CX3CR1 expression is not altered following trapezius muscle inflammation, although we cannot explain the reason why the IL-6 protein expression does not increase in this models. FKN protein expression, but not that of CX3CR1 which was expressed in microglia, was also significantly increased in Vc and C1-C2 following trapezius muscle inflammation, indicating that the increase of FKN shed by central terminals of trapezius muscle primary afferents after trapezius muscle inflammation may enhance signal transduction within the microglia via CX3CR1.

Microglia were not only activated in $\mathrm{C} 1-\mathrm{C} 2$, but also in Vc spinal segments after CFA injection into the trapezius muscle. Following successive intra-cisterna magna administration of anti-CX3CR1 neutralizing antibody, microglial activation was significantly suppressed in Vc and $\mathrm{C} 1-\mathrm{C} 2$ in CFA-injected rats. Microglial activation in $\mathrm{Vc}$ and $\mathrm{C} 1-\mathrm{C} 2$ was induced after intra-cisterna magna FKN administration. Moreover, rats with local inflammation in the trapezius muscle demonstrated mechanical allodynia in the lateral facial skin. The mechanical allodynia in the facial skin was depressed by successive intra-cisterna magna administration of anti-CX3CR1 neutralizing antibody. In addition, mechanical allodynia in the facial skin was induced after continuous intra-cisterna magna administration of FKN. Together, these results suggest that increased FKN shed from central terminal of trapezius muscle primary neurons in the $\mathrm{C} 1$ to the rostral $\mathrm{C} 6$ after trapezius muscle inflammation diffuses extensively in the spinal cord and binds to CX3CR1 in Vc and C1-C2 microglia, leading to their activation. Since microglia were also activated in Vc and C1-C2 after CFA injection into the facial skin and mechanical allodynia of the trapezius muscle was also induced by the facial skin inflammation, this microglial activation via FKN signaling may be involved in modulating mechanical sensitivity in areas remote from the inflamed region.
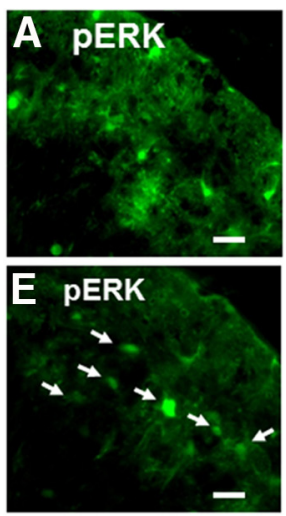

L
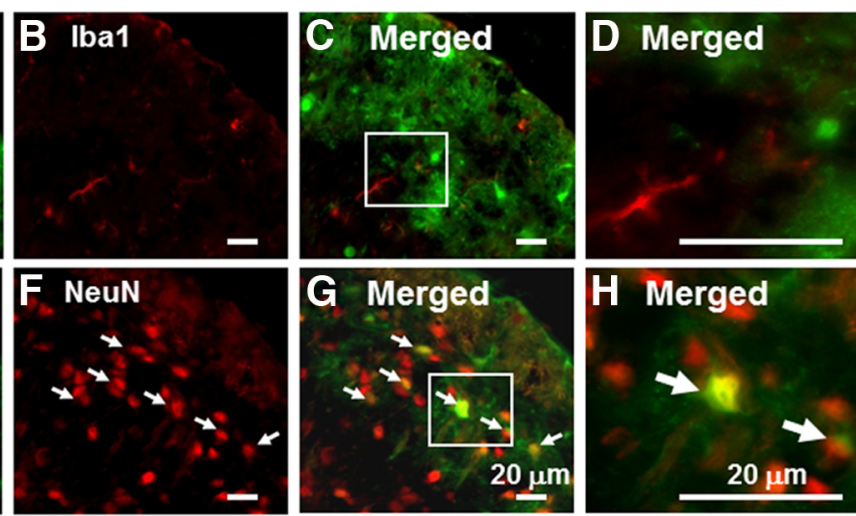

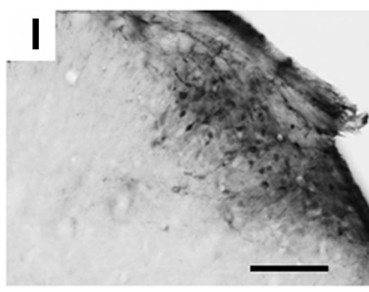

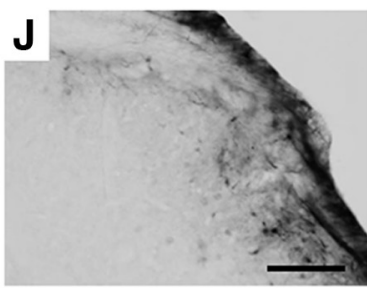

CFA/ i.c.m. anti-CX3CR1

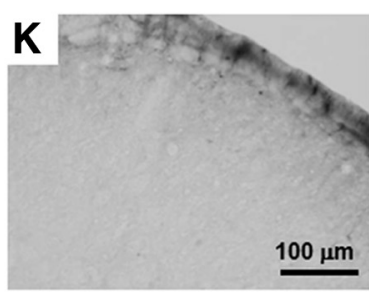

Saline/ i.c.m. Saline

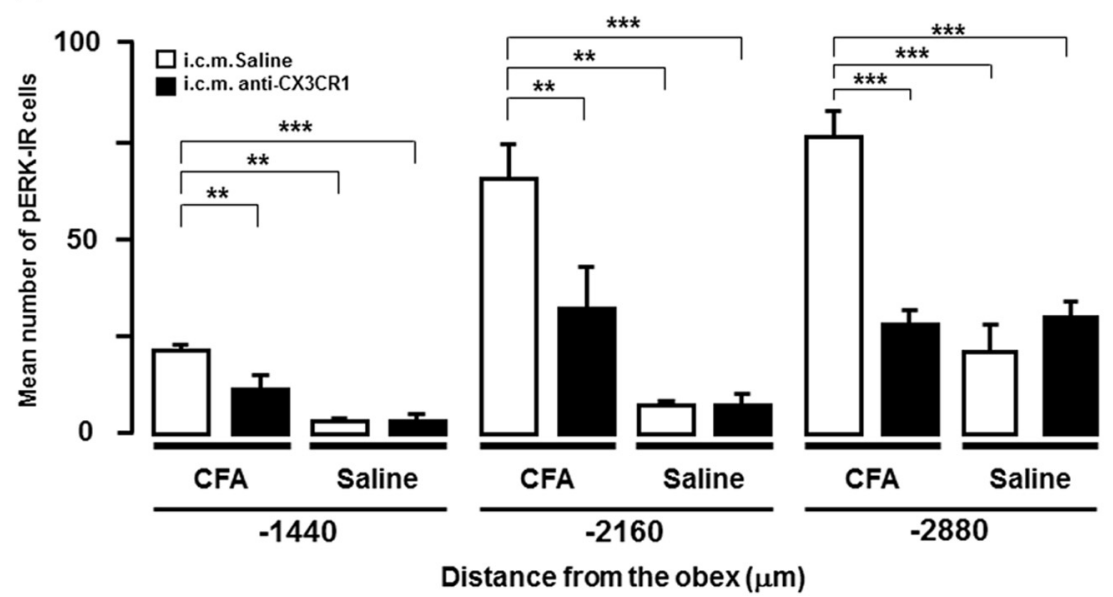

Figure 8. $A, B, C, E$, Photomicrographs of pERK-IR cells $(\boldsymbol{A}, \boldsymbol{E})$, Iba1-IR cells $(\boldsymbol{B})$, and pERK-IR and Iba1-IR cells $(\boldsymbol{C})$. D, Highmagnification photomicrograph of $\boldsymbol{C}$. $\boldsymbol{F}, \boldsymbol{G}$, Photomicrographs of NeuN-IR cells $(\boldsymbol{F})$ and pERK-IR and NeuN-IR cells $(\boldsymbol{G})$. $\boldsymbol{H}$, Highmagnification photomicrograph of $G$ in Vc and C1-C2 following noxious mechanical stimulation of facial skin on Day 4 after CFA injection. The arrows indicate double-IR cells in $\boldsymbol{E}-\boldsymbol{H}$. I, J, Photomicrographs of pERK-IR cells in Vc and C1-C2 following noxious mechanical stimulation of facial skin on Day 4 after (FA injection of saline (I) or anti-CX3CR1 neutralizing antibody (J) (intracisterna magna administration). $\boldsymbol{K}$, Photomicrographs of pERK-IR cells in Vc and C1-C2 following noxious mechanical stimulation of facial skin on Day 4 after saline injection with intra-cisterna magna saline administration. $L$, Changes in the number of pERK-IR e and C1-C2 following noxious mechanical stimulation of facial skin on Day 4 after saline or CFA injection with intracisterna magna saline or anti-CX3CR1 neutralizing antibody administration. ${ }^{* *} p<0.01$; ${ }^{* * *} p<0.001$ ( $n=5$ in each; one-way ANOVA followed by Newman-Keuls multiple-comparison tests). Error bars indicate SEM.

Spinal administration of FKN activates p38 (p38 phosphorylation), which is predominantly expressed in spinal microglia in naive rats, and intra-cisterna magna administration of a neutralizing antibody against CX3CR1 suppressed p38 phosphorylation after peripheral nerve injury, indicating that FKN signaling induces microglia activation via its sole receptor CX3CR1, and then activates p38 (Zhuang et al., 2007; Gao and Ji, 2010). Activation of p38 in microglia is now thought to be involved in the synthesis of proinflammatory cytokines such as TNF- $\alpha$, IL- $1 \beta$, and IL-6 after peripheral nerve injury (Ji and Suter, 2007). Moreover, BDNF production and release from microglia are mediated through p38 signaling pathways in vitro (Yang et al., 2012). In this 

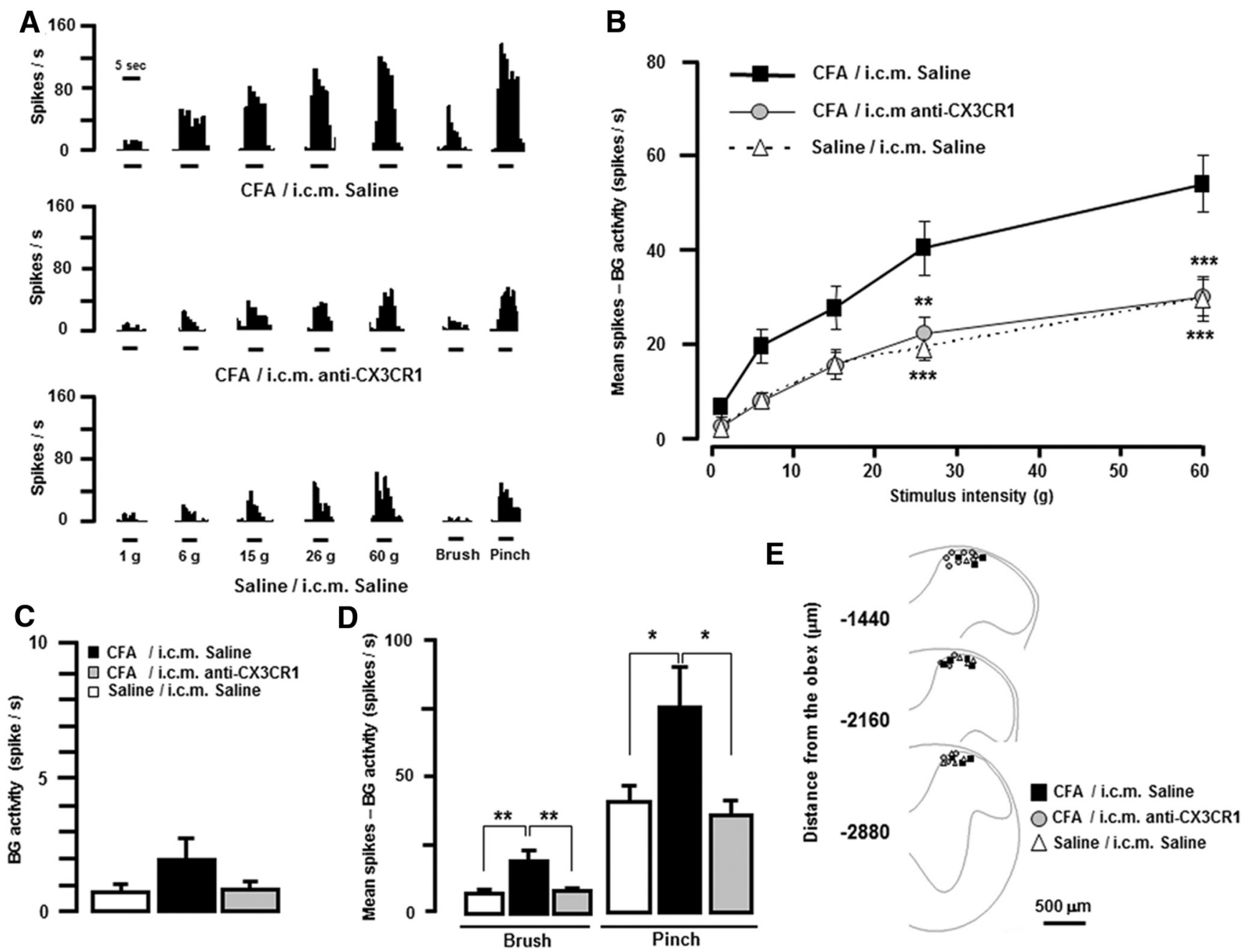

Figure 9. The effect of intra-cisterna magna administration of anti-CX3CR1 or saline on mechanical-evoked responses of V c and C1-C2 neurons on Day 4 after saline or CFA injection. $A$, Typical peristimulus time histograms of $\mathrm{Vc}$ and $(1-C 2$ WDR neurons to mechanical stimulus of the facial skin. $\boldsymbol{B}-\boldsymbol{D}$, WDR neuronal responses to mechanical stimuli by von Frey filament $(\boldsymbol{B})$, background activities (C), and brush or pinch stimuli (D) on Day 4 following saline or CFA injection with intra-cisterna magna saline or anti-CX3CR1 neutralizing antibody administration. ${ }^{*} p<0.05$; ${ }^{* *} p<0.01$; ${ }^{* * *} p<0.001$ (13 WDR neurons from 5 CFA-injected rats with intra-cisterna magna saline administration, 13 WDR neurons from 6 CFA-injected rats with intra-cisterna magna anti-CX3CR1 administration, 11 WDR neurons from 5 saline-injected rats with intra-cisterna magna saline administration; two-way ANOVA with repeated measures followed by Bonferroni's multiplecomparison tests or one-way ANOVA followed by Newman-Keuls multiple-comparison tests was performed where appropriate). $\boldsymbol{E}$, Recording sites in Vc and C1-C2 on Day 4 after saline or CFA injection with intra-cisterna magna saline or anti-CX3CR1 neutralizing antibody administration.

study, pp38 protein expression was significantly increased in microglia in Vc and C1-C2 after CFA-induced trapezius muscle inflammation. IL-1 $\beta$ protein expression was also significantly increased in $\mathrm{Vc}$ and $\mathrm{C} 1-\mathrm{C} 2$, but not in facial skin, following CFA injection into trapezius muscle. The IL- $1 \beta$ receptor was expressed in $\mathrm{Vc}$ and $\mathrm{C} 1-\mathrm{C} 2$ neurons, and mechanical allodynia in the lateral facial skin and was completely blocked by daily intracisterna magna anti-IL- $1 \beta$ neutralizing antibody administration in CFA-injected rats. Noxious mechanical-evoked responses of Vc and C1-C2 WDR neurons were significantly enhanced after CFA injection, and the evoked responses increased as mechanical stimulus intensity was increased. Such excitability increments are indicative of central sensitization, as described previously (Iwata et al., 1999; Dessem et al., 2007). Intra-cisterna magna administration of the anti-IL- $1 \beta$ neutralizing antibody significantly suppressed mechanical-evoked responses. These findings suggest that p 38 phosphorylation in activated microglia accelerates IL- $1 \beta$ release, and that mechanical allodynia of the lateral facial skin is induced by the enhancement of $\mathrm{Vc}$ and $\mathrm{C} 1-\mathrm{C} 2$ neuronal excitability via increased IL- $1 \beta$ signaling following CFA injection into the trapezius muscle. However, IL- $1 \beta$ receptor has also been shown to be expressed by presynaptic terminals and cell bodies of the primary afferent neurons, and the excitability is increased in DRG neurons via IL-1 $\beta$ signaling (Ebbinghaus et al., 2012; Stemkowski and Smith, 2012). We cannot rule out the possible effect of IL- $1 \beta$ on the primary afferent activity accounting for the enhancement of Vc and C1-C2 neuronal excitability.

ERK in dorsal horn neurons is phosphorylated by various types of noxious stimuli applied to the hind paw (Pezet et al., 2002). Strong noxious stimulation of peripheral tissues causes $\mathrm{Ca}^{2+}$ influx into the nociceptive dorsal horn neurons via NMDA receptors, resulting in ERK phosphorylation in the neurons (Xia et al., 1996). In the trigeminal system, ERK can be phosphorylated in a large number of dorsal horn neurons in the $\mathrm{Vc}$ and $\mathrm{C} 1-\mathrm{C} 2$ within $5 \mathrm{~min}$ after noxious stimulation into various orofacial regions; these pERK-IR neurons are somatotopically organized in $\mathrm{Vc}$ and $\mathrm{C} 1-\mathrm{C} 2$, and the number of pERK-IR neurons increases following increases in the noxious stimulus intensity (Honda et al., 2008; Noma et al., 2008). These data strongly indicate that ERK phosphorylation in $\mathrm{Vc}$ and $\mathrm{C} 1-\mathrm{C} 2$ neurons is a 


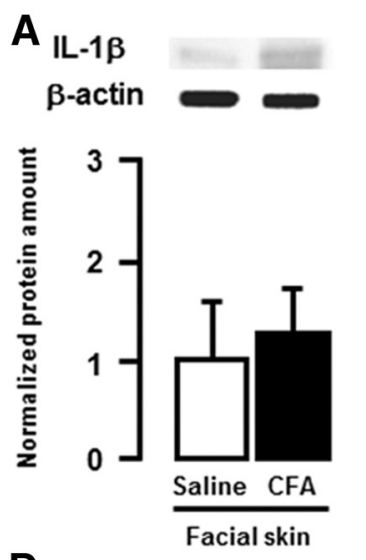

D

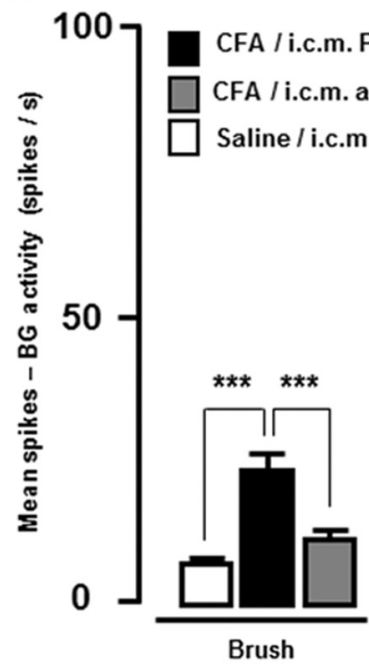

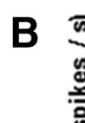

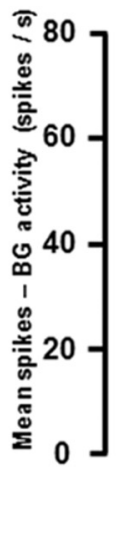

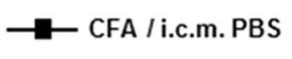

- - CFA / i.c.m. anti-IL-1 $\beta$

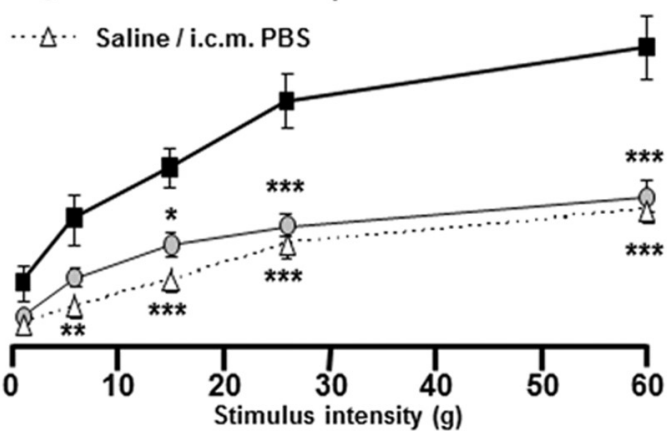

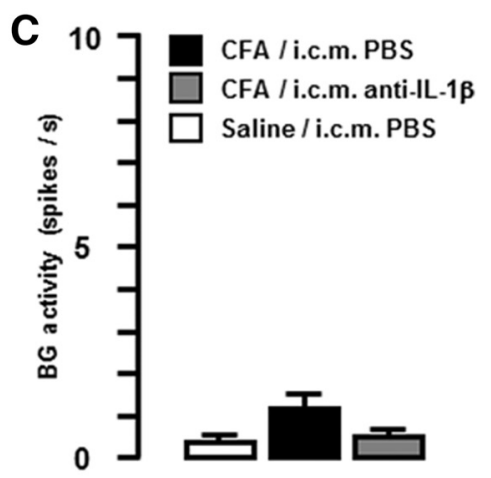

E

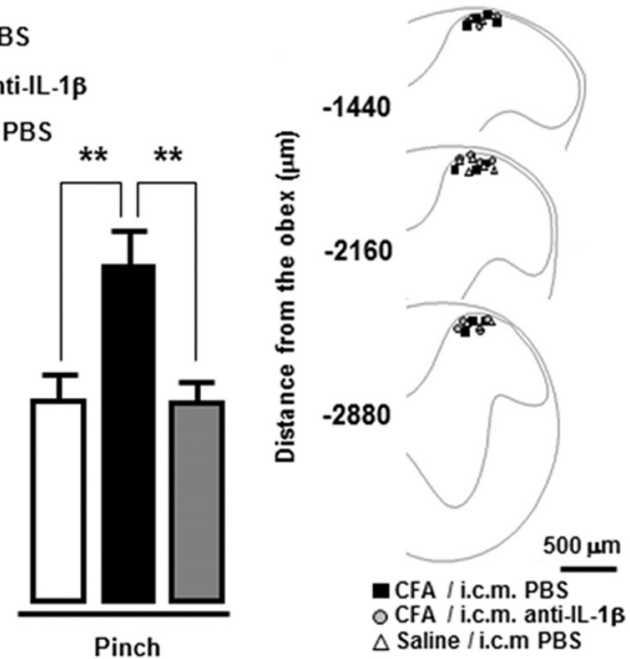

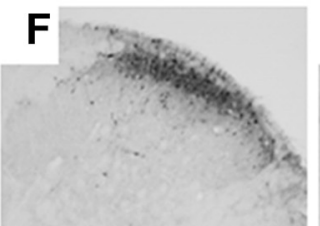

Naive (stim $60 \mathrm{~g} / 5 \mathrm{~min}$ )

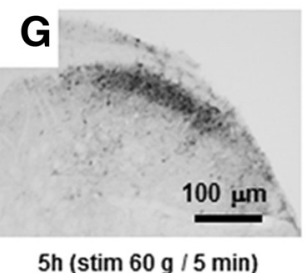

$\mathbf{H}$

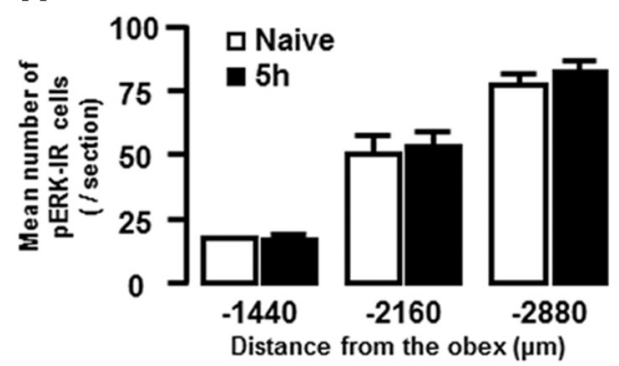

Figure 10. $\quad \boldsymbol{A}$, Normalized amount of IL-1 $\beta$ protein in the facial skin on Day 4 after CFA or saline injection into the trapezius muscle. $\beta$-actin was used as a loading control. $\boldsymbol{B}-\mathbf{D}$, The effect of intra-cisterna magna administration of anti-IL-1 $\beta$ or PBS on mechanical-evoked responses of $\mathrm{V}$ and $\mathrm{C} 1-\mathrm{C} 2$ neurons on Day 4 after saline or CFA injection. WDR responses to mechanical stimuli by von Frey filament $(\boldsymbol{B})$, background activities $(\boldsymbol{C})$, and brush or pinch stimuli $(\boldsymbol{D})$ on Day 4 following saline or CFA injection with intra-cisterna magna PBS or anti-IL-1 $\beta$ neutralizing antibody administration are shown. ${ }^{*} p<0.05 ;{ }^{* *} p<0.01 ; * * * 0.001$ (15 WDR neurons from 5 CFA-injected rats with intra-cisterna magna PBS administration, 15 WDR neurons from 5 CFA-injected rats with intra-cisterna magna anti-IL-1 $\beta$ administration, 15 WDR neurons from 5 saline-injected rats with intra-cisterna magna PBS administration; two-way ANOVA with repeated measures followed by Bonferroni's multiple-comparison tests or one-way ANOVA followed by Newman-Keuls multiple-comparison tests was performed where appropriate). $\boldsymbol{E}$, Recording sites in V c and (1-C2 on Day 4 after saline or CFA injection with intra-cisterna magna PBS or anti-IL-1 $\beta$ neutralizing antibody administration. $\boldsymbol{F}, \mathbf{G}$, Photomicrographs of pERK-IR cells in Vc in naive rats $(\boldsymbol{F})$ and rats with $5 \mathrm{~h}$ exposure of the recording area (G). $\boldsymbol{H}$, Mean number of pERK-IR cells in Vc and C1-C2 in naive rats and rats with 5 h exposure of the recording area $(n=5$ in each).

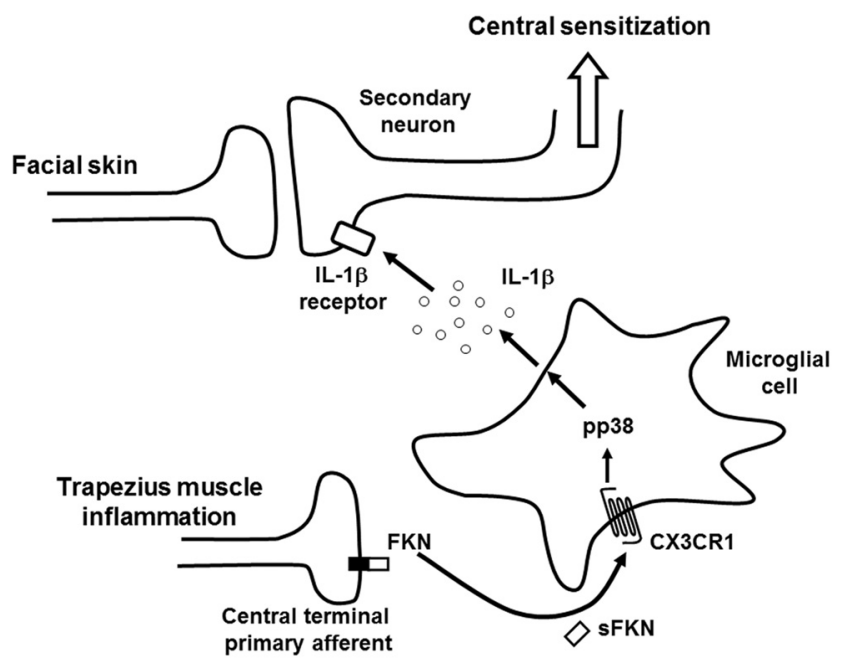

Figure 11. Schematic presentation of FKN contribution to ectopic mechanical allodynia of facial skin caused by trapezius muscle inflammation. Secondary neurons in V and C1-C2 sensitized by microglial activation via FKN signaling may facilitate the transmission of nociceptive information from facial skin. reliable marker of excitable neurons following orofacial noxious stimulation. In this study, ERK phosphorylation was accelerated in neurons in the superficial laminae of Vc and C1-C2 following noxious mechanical stimulation of the facial skin in CFA-injected rats, and the number of pERK-IR cells in Vc and C1-C2 was significantly depressed after CFA injection by daily intra-cisterna magna anti-CX3CR1 neutralizing antibody administration, indicating that anti-CX3CR1 neutralizing antibody significantly attenuated ERK phosphorylation in $\mathrm{Vc}$ and $\mathrm{C} 1-\mathrm{C} 2$ neurons. Noxious-evoked responses in Vc and C1-C2 WDR neurons were significantly enhanced after CFA injection, and the evoked responses showed an increase in their firings following an increase in mechanical stimulus intensity. Intra-cisterna magna administration of the anti-CX3CR1 neutralizing antibody also significantly suppressed the mechanical evoked responses. Together, the present results suggest that microglial activation via FKN signaling is involved in the modulation of neuronal excitability induced by noxious stimulation to the facial skin after trapezius muscle inflammation. Primary afferents innervating the trapezius muscle are known to terminate in the C2 to C6 segments of 
the spinal cord (Ishii, 1989), indicating that FKN is shed from central terminals of trapezius muscle afferents in the C2 to C6 after trapezius muscle inflammation. Moreover, ERK was phosphorylated in Vc and C1-C2 neurons following capsaicin injection into the lateral facial skin (Noma et al., 2008), indicating that facial skin afferents project to Vc and $\mathrm{C} 1-\mathrm{C} 2$ spinal segments. In this study, there was rarely overlap in the pERK-IR cell distribution in medullae and spinal cord after capsaicin injection into facial skin and trapezius muscle, respectively. These findings indicate that central terminals of the facial skin-afferents mainly contact with $\mathrm{Vc}$ and $\mathrm{C} 1-\mathrm{C} 2$ neurons, which rarely contact with those of the trapezius muscle afferents, suggesting that the enhancement of excitability in Vc and $\mathrm{C} 1-\mathrm{C} 2$ neurons were indirectly induced via microglial activation, but not directly via enhanced trapezius muscle afferents.

In conclusion, we have developed a new model of ectopic orofacial pain following the trapezius muscle inflammation, which resulted in mechanical allodynia in the facial skin. The release of FKN in C2-C6 was enhanced following trapezius muscle inflammation, and microglia in $\mathrm{Vc}$ and $\mathrm{C} 1-\mathrm{C} 2$ were activated via FKN signaling. In addition, IL- $1 \beta$ release was accelerated through p38 phosphorylation followed by microglial activation, and the excitability of $\mathrm{Vc}$ and $\mathrm{C} 1-\mathrm{C} 2$ neurons was enhanced via IL- $1 \beta$ signaling. The enhancement of excitability of Vc and C1-C2 WDR neurons after trapezius muscle inflammation may contribute to the resulting ectopic mechanical allodynia (Fig. 11). The findings raise the possibility that FKN signaling may be a promising therapeutic target for treating orofacial pain associated with back and neck pain.

\section{References}

Barclay J, Clark AK, Ganju P, Gentry C, Patel S, Wotherspoon G, Buxton F, Song C, Ullah J, Winter J, Fox A, Bevan S, Malcangio M (2007) Role of the cysteine protease cathepsin S in neuropathic hyperalgesia. Pain 130: 225-234. CrossRef Medline

Bazan JF, Bacon KB, Hardiman G, Wang W, Soo K, Rossi D, Greaves DR, Zlotnik A, Schall TJ (1997) A new class of membrane-bound chemokine with a CX3C motif. Nature 385:640-644. CrossRef Medline

Clark AK, Malcangio M (2012) Microglial signalling mechanisms: Cathepsin S and Fractalkine. Exp Neurol 234:283-292. CrossRef Medline

Clark AK, Yip PK, Grist J, Gentry C, Staniland AA, Marchand F, Dehvari M, Wotherspoon G, Winter J, Ullah J, Bevan S, Malcangio M (2007) Inhibition of spinal microglial cathepsin $\mathrm{S}$ for the reversal of neuropathic pain. Proc Natl Acad Sci U S A 104:10655-10660. CrossRef Medline

Clark AK, Yip PK, Malcangio M (2009) The liberation of fractalkine in the dorsal horn requires microglial cathepsin S. J Neurosci 29:6945-6954. CrossRef Medline

Dessem D, Moritani M, Ambalavanar R (2007) Nociceptive craniofacial muscle primary afferent neurons synapse in both the rostral and caudal brain stem. J Neurophysiol 98:214-223. CrossRef Medline

Ebbinghaus M, Uhlig B, Richter F, von Banchet GS, Gajda M, Bräuer R, Schaible HG (2012) The role of interleukin-1beta in arthritic pain: main involvement in thermal, but not mechanical, hyperalgesia in rat antigeninduced arthritis. Arthritis Rheum 64:3897-3907. CrossRef Medline

Fernández-de-Las-Peñas C, Galán-Del-Río F, Alonso-Blanco C, JiménezGarcía R, Arendt-Nielsen L, Svensson P (2010) Referred pain from muscle trigger points in the masticatory and neck-shoulder musculature in women with temporomandibular disorders. J Pain 11:1295-1304. CrossRef Medline

Gao YJ, Ji RR (2010) Chemokines, neuronal-glial interactions, and central processing of neuropathic pain. Pharmacol Ther 126:56-68. CrossRef Medline

Haraguchi K, Kawamoto A, Isami K, Maeda S, Kusano A, Asakura K, Shirakawa H, Mori Y, Nakagawa T, Kaneko S (2012) TRPM2 contributes to inflammatory and neuropathic pain through the aggravation of pronociceptive inflammatory responses in mice. J Neurosci 32:3931-3941. CrossRef Medline

Honda K, Kitagawa J, Sessle BJ, Kondo M, Tsuboi Y, Yonehara Y, Iwata K
(2008) Mechanisms involved in an increment of multimodal excitability of medullary and upper cervical dorsal horn neurons following cutaneous capsaicin treatment. Mol Pain 4:59. CrossRef Medline

Imai Y, Kohsaka S (2002) Intracellular signaling in M-CSF-induced microglia activation: role of Iba1. Glia 40:164-174. CrossRef Medline

Imai Y, Ibata I, Ito D, Ohsawa K, Kohsaka S (1996) A novel gene ibal in the major histocompatibility complex class III region encoding an EF hand protein expressed in a monocytic lineage. Biochem Biophys Res Commun 224:855-862. CrossRef Medline

Ishii Y (1989) [Central afferent projections from the rat sternocleidomastoid and trapezius muscles. A study using transganglionic transport of horseradish peroxidase] (in Japanese). Osaka Daigaku Shigaku Zasshi 34:193-212. Medline

Iwata K, Tashiro A, Tsuboi Y, Imai T, Sumino R, Morimoto T, Dubner R, Ren K (1999) Medullary dorsal horn neuronal activity in rats with persistent temporomandibular joint and perioral inflammation. J Neurophysiol 82: 1244-1253. Medline

Iwata K, Imai T, Tsuboi Y, Tashiro A, Ogawa A, Morimoto T, Masuda Y, Tachibana Y, Hu J (2001) Alteration of medullary dorsal horn neuronal activity following inferior alveolar nerve transection in rats. J Neurophysiol 86:2868-2877. Medline

Ji RR, Suter MR (2007) p38 MAPK, microglial signaling, and neuropathic pain. Mol Pain 3:33. CrossRef Medline

Kitagawa J, Takeda M, Suzuki I, Kadoi J, Tsuboi Y, Honda K, Matsumoto S, Nakagawa H, Tanabe A, Iwata K (2006) Mechanisms involved in modulation of trigeminal primary afferent activity in rats with peripheral mononeuropathy. Eur J Neurosci 24:1976-1986. CrossRef Medline

Lee KM, Jeon SM, Cho HJ (2010) Interleukin-6 induces microglial CX3CR1 expression in the spinal cord after peripheral nerve injury through the activation of p38 MAPK. Eur J Pain 14:682.e1-12. Medline

Lindia JA, McGowan E, Jochnowitz N, Abbadie C (2005) Induction of CX3CL1 expression in astrocytes and CX3CR1 in microglia in the spinal cord of a rat model of neuropathic pain. J Pain 6:434-438. CrossRef Medline

Marini I, Bartolucci ML, Bortolotti F, Gatto MR, Bonetti GA (2012) Palmitoylethanolamide versus a nonsteroidal anti-inflammatory drug in the treatment of temporomandibular joint inflammatory pain. J Orofac Pain 26:99-104. Medline

Nishiyori A, Minami M, Ohtani Y, Takami S, Yamamoto J, Kawaguchi N, Kume T, Akaike A, Satoh M (1998) Localization of fractalkine and CX3CR1 mRNAs in rat brain: does fractalkine play a role in signaling from neuron to microglia? FEBS Lett 429:167-172. CrossRef Medline

Noma N, Tsuboi Y, Kondo M, Matsumoto M, Sessle BJ, Kitagawa J, Saito K, Iwata K (2008) Organization of pERK-immunoreactive cells in trigeminal spinal nucleus caudalis and upper cervical cord following capsaicin injection into oral and craniofacial regions in rats. J Comp Neurol 507: 1428-1440. CrossRef Medline

Pezet S, Malcangio M, Lever IJ, Perkinton MS, Thompson SW, Williams RJ, McMahon SB (2002) Noxious stimulation induces Trk receptor and downstream ERK phosphorylation in spinal dorsal horn. Mol Cell Neurosci 21:684-695. CrossRef Medline

Raghavendra V, Tanga FY, DeLeo JA (2004) Complete Freunds adjuvantinduced peripheral inflammation evokes glial activation and proinflammatory cytokine expression in the CNS. Eur J Neurosci 20:467-473. CrossRef Medline

Ren K, Torres R (2009) Role of interleukin-1beta during pain and inflammation. Brain Res Rev 60:57-64. CrossRef Medline

Savarin-Vuaillat C, Ransohoff RM (2007) Chemokines and chemokine receptors in neurological disease: raise, retain, or reduce? Neurotherapeutics 4:590-601. CrossRef Medline

Sharma N, Thomas S, Ho L, Reyes DC, Sacerdote P, Bianchi M, Pasinetti GM (2008) Immunomodulation with glatiramer acetate prevents long-term inflammatory pain. Int J Neurosci 118:433-453. CrossRef Medline

Shinoda M, Ozaki N, Asai H, Nagamine K, Sugiura Y (2005) Changes in $\mathrm{P} 2 \mathrm{X} 3$ receptor expression in the trigeminal ganglion following monoarthritis of the temporomandibular joint in rats. Pain 116:42-51. CrossRef Medline

Shinoda M, Asano M, Omagari D, Honda K, Hitomi S, Katagiri A, Iwata K (2011) Nerve growth factor contribution via transient receptor potential vanilloid 1 to ectopic orofacial pain. J Neurosci 31:7145-7155. CrossRef Medline

Staniland AA, Clark AK, Wodarski R, Sasso O, Maione F, D'Acquisto F, 
Malcangio M (2010) Reduced inflammatory and neuropathic pain and decreased spinal microglial response in fractalkine receptor (CX3CR1) knockout mice. J Neurochem 114:1143-1157. Medline

Stemkowski PL, Smith PA (2012) Long-term IL-1beta exposure causes subpopulation-dependent alterations in rat dorsal root ganglion neuron excitability. J Neurophysiol 107:1586-1597. CrossRef Medline

Takemura M, Sugimoto T, Shigenaga Y (1991) Difference in central projection of primary afferents innervating facial and intraoral structures in the rat. Exp Neurol 111:324-331. CrossRef Medline

Terayama R, Omura S, Fujisawa N, Yamaai T, Ichikawa H, Sugimoto T (2008) Activation of microglia and p38 mitogen-activated protein kinase in the dorsal column nucleus contributes to tactile allodynia following peripheral nerve injury. Neuroscience 153:1245-1255. CrossRef Medline

Tsuboi Y, Iwata K, Dostrovsky JO, Chiang CY, Sessle BJ, Hu JW (2011) Modulation of astroglial glutamine synthetase activity affects nociceptive behaviour and central sensitization of medullary dorsal horn nociceptive neurons in a rat model of chronic pulpitis. Eur J Neurosci 34:292-302. CrossRef Medline

Verge GM, Milligan ED, Maier SF, Watkins LR, Naeve GS, Foster AC (2004) Fractalkine (CX3CL1) and fractalkine receptor (CX3CR1) distribution in spinal cord and dorsal root ganglia under basal and neuropathic pain conditions. Eur J Neurosci 20:1150-1160. CrossRef Medline
Xia Z, Dudek H, Miranti CK, Greenberg ME (1996) Calcium influx via the NMDA receptor induces immediate early gene transcription by a MAP kinase/ERK-dependent mechanism. J Neurosci 16:5425-5436. Medline

Yang H, Feng GD, Liang Z, Vitale A, Jiao XY, Ju G, You SW (2012) In vitro beneficial activation of microglial cells by mechanically-injured astrocytes enhances the synthesis and secretion of BDNF through p38MAPK. Neurochem Int 61:175-186. CrossRef Medline

Zhang W, Wang T, Pei Z, Miller DS, Wu X, Block ML, Wilson B, Zhang W, Zhou Y, Hong JS, Zhang J (2005) Aggregated alpha-synuclein activates microglia: a process leading to disease progression in Parkinson's disease. FASEB J 19:533-542. CrossRef Medline

Zhang Z, Dellon AL (2008) Facial pain and headache associated with brachial plexus compression in the thoracic inlet. Microsurgery 28: 347-350. CrossRef Medline

Zhuang ZY, Kawasaki Y, Tan PH, Wen YR, Huang J, Ji RR (2007) Role of the CX3CR1/p38 MAPK pathway in spinal microglia for the development of neuropathic pain following nerve injury-induced cleavage of fractalkine. Brain Behav Immun 21:642-651. CrossRef Medline

Zimmermann M (1983) Ethical guidelines for investigations of experimental pain in conscious animals. Pain 16:109-110. CrossRef Medline 